Article

\title{
Detection of Coal Fire Dynamics and Propagation Direction from Multi-Temporal Nighttime Landsat SWIR and TIR Data: A Case Study on the Rujigou Coalfield, Northwest (NW) China
}

\author{
Hongyuan Huo ${ }^{1,2}$, Xiaoguang Jiang ${ }^{1}$, Xianfeng Song ${ }^{1, *}$, Zhao-Liang $\mathrm{Li}^{2,3}$, Zhuoya Ni ${ }^{2,4}$ \\ and Caixia Gao ${ }^{5}$
}

1 College of Resources and Environment, University of Chinese Academy of Sciences, Beijing 100049, China; E-Mails: huohongyuan2008@163.com (H.H.); xgjiang@aoe.ac.cn (X.J.)

2 ICube, CNRS, Université de Strasbourg, Boulevard Sebastien Brant, BP10413, F-67412 Illkirch, France; E-Mails: lizl@unistra.fr (Z-L.L.); nizhuoya@gmail.com (Z.N.)

3 Key Laboratory of Agri-informatics, Ministry of Agriculture/Institute of Agricultural Resources and Regional Planning, Chinese Academy of Agricultural Sciences, Beijing 100081, China

4 School of Geography, Beijing Normal University, Beijing 100875, China

5 Academy of Opto-Electronics, Chinese Academy of Sciences, Beijing 100094, China; E-Mail: caixiagao2010@hotmail.com

* Author to whom correspondence should be addressed; E-Mail: song7537338@163.com; Tel.: +86-10-8825-6890; Fax: +86-10-8825-6145.

Received: 2 December 2013; in revised form: 24 December 2013 / Accepted: 15 January 2014 / Published: 29 January 2014

\begin{abstract}
Coal fires are common and serious phenomena in most coal-producing countries in the world. Coal fires not only burn valuable non-renewable coal reserves but also severely affect the local and global environment. The Rujigou coalfield in Shizuishan City, Ningxia, NW China, is well known for being a storehouse of anthracite coal. This coalfield is also known for having more coal fires than most other coalfields in China. In this study, an attempt was made to study the dynamics of coal fires in the Rujigou coalfield, from 2001 to 2007, using multi-temporal nighttime Landsat data. The multi-temporal nighttime short wave infrared (SWIR) data sets based on a fixed thresholding technique were used to detect and monitor the surface coal fires and the nighttime enhanced thematic mapper (ETM + ) thermal infrared (TIR) data sets, based on a dynamic thresholding technique, were used to identify the thermal anomalies related to subsurface coal fires. By validating the coal fires identified in the nighttime satellite data and the coal fires extracted from daytime satellite data with the coal fire map (CFM) manufactured by field survey, we found that the results
\end{abstract}


from the daytime satellite data had higher omission and commission errors than the results from the nighttime satellite data. Then, two aspects of coal fire dynamics were analyzed: first, a quantitative analysis of the spatial changes in the extent of coal fires was conducted and the results showed that, from 2001 to 2007, the spatial extent of coal fires increased greatly to an annual average area of $0.167 \mathrm{~km}^{2}$; second, the spreading direction and propagation of coal fires was analyzed and predicted from 2001 to 2007, and these results showed that the coal fires generally spread towards the north or northeast, but also spread in some places toward the east.

Keywords: multi-temporal remote sensing; dynamics; coal fires; thresholding technique; TM; ETM+

\section{Introduction}

Coal fires, also called coal seam fires, are caused by the spontaneous combustion of coal during coal oxidation [1]. Schmal et al. (1985) noted that the potential of spontaneous combustion of coal may enhance its ability to react with oxygen at ambient temperatures [2]; at the same time, this reaction is exothermic because it is accompanied by the absorption of oxygen at the surface of the coal field, which may increase the "threshold" temperature, which is between $230{ }^{\circ} \mathrm{C}$ and $280{ }^{\circ} \mathrm{C}$. At this temperature, coal reaches its "ignition" or "flash" point and starts to burn, resulting in a coal fire.

Figure 1. Chinese fired coal and Chinese coal production since 1902.

\section{Chinese Fired Coal and Chinese Coal Production}

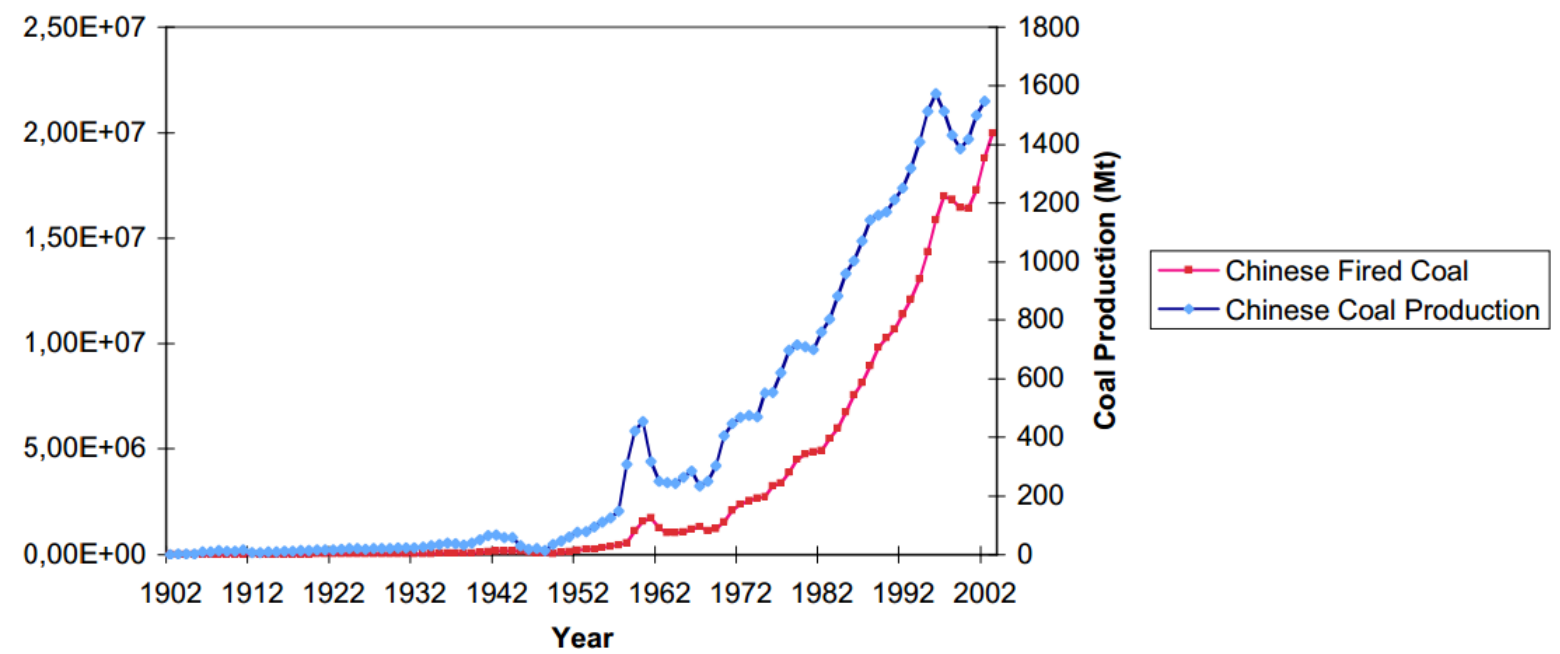

Uncontrolled coal fires can cause many problems and are serious hazards because they may produce severe and long-term impacts on the local life, economy, and local and even global environment [3-8]. This phenomenon is very common in coal-producing countries, especially in China. Spontaneous combustion of coal was widespread in the North China Coal Field: more than 100 coal fires with a total area of approximately $720 \mathrm{~km}^{2}$ have caused an average annual coal loss of 10-20 million tons through 
burning, and have indirectly affected coal mining by putting approximately 200 million tons of coal out of practical mining reach each year (Figure 1) [1,9,10]. Furthermore, coal fires emit large amounts of greenhouse gases (GHGs) and toxic gases, including $\mathrm{CO}_{2}, \mathrm{CH}_{4}, \mathrm{NO}, \mathrm{N}_{2} \mathrm{O}, \mathrm{CO}$, and $\mathrm{SO}_{2}$, which cause severe environmental problems, e.g., land degradation, global warming, and air pollution [11-14].

To control and mitigate coal fires, scientists in various countries have investigated coal combustion [15-18]. Borehole temperature measurements were the primary tool used to detect underground coal fires until 1963, when the United States began to use thermal remote sensing (TIR) techniques to detect and monitor coal fires $[6,15,19]$. Since then, TIR has proven to be a reliable and useful tool for identifying and monitoring underground coal fires. A review monitoring coal fires based on the TIR approach was conducted by Zhang et al. [6]. The TIR approach can be classified by the sensors used: there are airborne thermal remote sensing (ATIR) and space-borne thermal remote sensing (STIR), both of which have been widely used to monitor coal fires. Using ATIR data over a spectral region from 8 to $13 \mu \mathrm{m}$, Green et al. reported 22 coal mine fires in the anthracite fields of Pennsylvania, USA [20]. Other studies conducted similar experiments [21-23]. Due to the rapid development of remote sensing techniques, additional airborne sensors have been widely used in the study of coal fires [24,25]. However, considering the high price for data acquisition by airborne scanners, many scientists are seeking a satellite thermal remote sensing approach as an available and economic substitute for coal fire identification and monitoring. The STIR and mid-infrared (MIR) spectral region include data with low spatial resolution, such as the Advanced Very High Resolution Radiometer (AVHRR) and the Moderate Resolution Imaging Spectroradiometer (MODIS), as well as data with higher spatial resolution, such as Landsat Thematic Mapper/Enhanced Thematic Mapper (TM/ETM+) and the Advanced Spaceborne Thermal Emission and Reflection Radiometer (ASTER); the space-borne remote sensing data within MIR spectral region with a relative high spatial resolution such as the experimental Bi-spectral Infrared Detection (BIRD); data from all these instruments have been used to detect and monitor coal fires [26-30]. In general, the methods for coal fire identification and monitoring can be grouped into four classes: (1) the density slicing method, which has been successfully applied to extract coal fire information from LandSat-5/7 TM/ETM+ data [11,25,29,31]; (2) the automated or semi-automated method, which has been successfully applied to extract surface and subsurface coal fires from background information, based on statistical parameters [19,28,32]; (3) the fixed-threshold method with the multi-spectral method [33]; and (4) the dual-band method proposed by Dozier (1981), and Matson and Dozier (1981), which has been successfully applied to coal fire identification in many studies $[31,34,35]$. Despite these significant contributions, no substantial research has yet attempted to study the dynamics of surface and subsurface coal fires using nighttime ETM+ SWIR band 7 data and ETM+ thermal band 6 data. In particular, no study has sought to detect temporal changes in the spreading directions of coal fires in China using multi-temporal nighttime Landsat ETM+ SWIR and thermal data. The objectives of this paper are (1) to detect the dynamics of subsurface coal fires using multi-temporal nighttime Landsat ETM+ thermal band 6 data; (2) to detect the dynamics of surface coal fires using multi-temporal nighttime Landsat ETM+ SWIR band 7 data; (3) to analyze the spatial relationship between surface coal fires and subsurface coal fires; (4) to determine which datasets are available to detect the coal fire spreading direction by conducting a comparative analysis between the coal fires from nighttime satellite data and the coal fires from daytime satellite data and to validate these data using field survey maps; and (5) to delineate the directions of propagation of coal fires. While the 
focus of the study is to analyze the nighttime-satellite-detected coal fire spreading directions, the results should also be useful to the efforts of the local mining bureau to extinguish the coal fires and for environmental management.

The assessment of the spread of coal fires and their dynamics is important for estimating losses of this non-renewable resource. The detection of the spreading direction of these coal fires will be helpful in predicting the velocity of coal fire expansion and the extent of coal fire development. These findings will be beneficial for coal mining activities and for enhancing the safety of miners. In this study, we used nocturnal multi-temporal Landsat ETM+ thermal band 6 data and SWIR band 7 data to detect underground coal fires and surface coal fires, respectively, and also to detect and monitor the spreading direction of the coal fires. The Landsat TM band 6 data, which has a spatial resolution of $120 \mathrm{~m}$, has been widely used for detecting underground coal fires [7,17,28,36,37], but almost all the datasets used in these studies were daytime band 6 images, and these studies used the density slicing method almost exclusively. Because the spatial resolution of the TM band 6 data $(120 \mathrm{~m})$ is coarser than that of the ETM+ band 6 data $(60 \mathrm{~m})$, small and deep coal fires may not be detected [38]. However, this is an advantage that eases the removal of daytime solar irradiance, and the nocturnal Landsat ETM+ band 6 data, with its higher spatial resolution data, will be preferable in this situation. Furthermore, because the saturation of the ETM+ thermal band 6 data is approximately $70{ }^{\circ} \mathrm{C}$, which is the same as the TM thermal band 6 data, while the temperature range of subsurface coal fires is usually cooler than this, ETM+ thermal band 6 images are very useful for detecting subsurface coal fires.

The Landsat SWIR band 7 data have been used for detecting the high extensive heat sources (e.g., volcanoes, forest fires, and surface coal fires) since the 1990 s by many scientists, as these extensive, high-magnitude heat sources often cause great increases in radiance in SWIR imagery [17,31,35,39]. Most studies used diurnal SWIR band 7 data combined with band 5 data to calculate the temperature, based on the dual-band method. In this study, the single SWIR band 7 data were used. The temperature range that band 7 data is sensitive to is $160-277^{\circ} \mathrm{C}$, which matches very well to the temperature range of surface coal fires $\left(150-250^{\circ} \mathrm{C}\right)$; therefore, the SWIR band 7 data can be used to detect very hot pixels $\left(>70{ }^{\circ} \mathrm{C}\right)$, unlike the ETM+ thermal band 6 data, of which maximum temperature is approximately $70^{\circ} \mathrm{C}$. In the paper, the ETM+SWIR band 7 data are used to detect surface coal fires based on a thresholding technique. Unlike the ETM+ band 6 data, which has a thermal spectral region in which the reflected solar irradiance can be negligible, thermal radiance at the diurnal SWIR spectral region is combined with the solar radiation reflected by the surface and scattered due to atmospheric effects. Therefore, the nocturnal ETM+ band 7 data will improve this situation even without considering the effects of solar irradiance on the nighttime data of the SWIR spectral region.

In the paper, an introduction to the geology and terrain of the study area is described in Section 2 . The data used in the study, their preprocessing and the flowchart of the research are given in Section 3. Detailed information on the methodology of temperature retrieval, based on the nocturnal multi-temporal Landsat thermal band 6 and SWIR band 7 data, to detect and monitor the coal fires is given in Section 4. In Section 5, the results of coal fire identification are validated by a map generated by field survey; surface and subsurface coal fires are extracted from nighttime thermal band 6 and SWIR band 7 data, respectively, and are counted; a quantitative analysis is developed to detect the annual dynamics of coal fires from 2001 to 2007; and the spreading direction of coal fires is predicted. Finally, a conclusion is made and potential problems that need to be resolved in future research are identified. 


\section{Study Area}

The Rujigou coalfield is located in the Helan Mountains at elevations between 1,800 and 2,500 $\mathrm{m}$ in the city of Shizuishan (Figure 2b), Ningxia, NW China (Figure 2). The coal-bearing sediments of the Rujigou coalfield were deposited in the rivers and lakes of a Middle Jurassic continental basin that was free of marine influences. The rocks of the coalfield are widely folded in a NE-SW striking synclinal structure. Within the $15 \mathrm{~km}$ by $8 \mathrm{~km}$ coalfield, seven coal seams have an average thickness of $20 \mathrm{~m}$. As its coal is of high quality, ranging from low volatile to anthracite coal, the Rujigou coalfield is heavily mined and is mostly covered by bare rocks. The Ningxia Hui Autonomous Region is a part of the central Asian grassland and desert region, thus, the Rujigou coalfield has a continental climate with long, cold winters and very hot, dry summers; the average annual precipitation is $238 \mathrm{~mm}$. This climate puts the coal seams at risk because the outcrops of coal are exposed to the elements, which can easily cause spontaneous combustion. Most of the coal seams in the region are affected by uncontrolled fires. Approximately 45 private mines still exist next to some of the major mines in the Rujigou coalfield; in recent years, the coalfield has been affected by over 20 coal fires (Figure 2c).

Figure 2. Study area of Rujigou Coal Field: (a) shows the location and direction of study area in Northwest China, (b) shows the Rujigou Coal Field located in the Rujigou district, in Shizuishan city and (c) is a 3-D FCC (False Color Composite) image (generated by coding $\mathrm{ETM}+7 / 4 / 2$ in R/G/B) based on Landsat ETM+ data acquired on 12 August 1999, overlaid by coal fire map from local mineral bureau, obtained from a field survey of 2002-2003, Projection: UTM, zone 48 North, WGS 84.

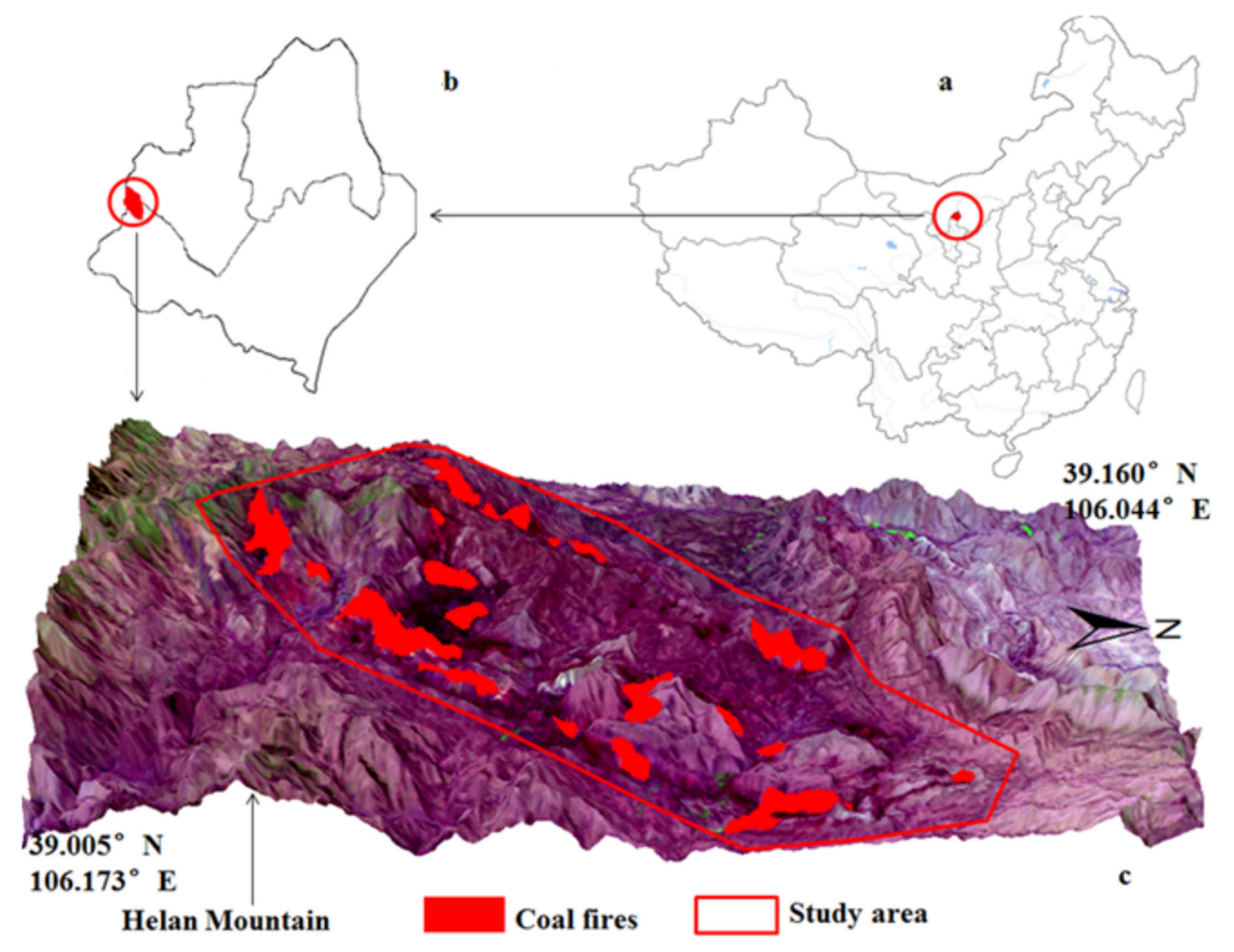




\section{Data Used and Preprocessing}

In this study, nighttime cloud-free Landsat-7 ETM+ TIR band images with $60-\mathrm{m}$ spatial resolution were collected (Table 1). All the nighttime Landsat TM/ETM+ thermal datasets were the standard terrain correction (L1T) products, downloaded from the United States Geological Survey (USGS) website, which provides systematic radiometric and geometric accuracy estimates by incorporating ground control points (GCPs) from the global land survey of 2000 (GLS2000) and employing a digital elevation model (DEM) for topographic accuracy. DEM sources include the Shuttle Radar Topography Mission (SRTM), the National Elevation Dataset (NED), Canadian Digital Elevation Data (CDED), Digital Terrain Elevation Data (DTED), and GTOPO 30 (a global DEM from the USGS). In this paper, the data used for the study were grouped into two categories: the nighttime data were used to calculate the temperature of the coalfields, and the daytime data were used to calculate the emissivities of the coalfields. As none of the daytime data were synchronous with the nighttime images, cloud-free daytime datasets with acquisition times, seasons, and years chosen to match as well as possible those of the corresponding nighttime ETM+ data were acquired for calculating the emissivity (Table 2).

Table 1. The Landsat data used for temperature retrieval to coal fire detection and monitoring in the study.

\begin{tabular}{cccc}
\hline Data Type & Band Used for Temperature & Respective Spatial Resolution (m) & Time of Data Acquisition \\
\hline Nighttime Landsat 7 & 6,7 & $60 / 30$ & 9 September 2001 \\
Nighttime Landsat 7 & 6,7 & $60 / 30$ & 28 September 2002 \\
Nighttime Landsat 7 & 6,7 & $60 / 30$ & 8 July 2007 \\
\hline
\end{tabular}

Table 2. The Landsat data used for normalized difference vegetation index (NDVI) to calculate the respective emissivities of multi-temporal satellite data in the study.

\begin{tabular}{cccc}
\hline Data Type & Bands Used for NDVI & Respective Spatial Resolution (m) & Time of Data Acquisition \\
\hline Daytime Landsat 5 & 3,4 & 30 & 10 September 2001 \\
Daytime Landsat 7 & 3,4 & 30 & 21 September 2002 \\
Daytime Landsat 5 & 3,4 & 30 & 23 June 2007 \\
\hline
\end{tabular}

One data preprocessing problem that needs to be resolved concerns the nonfunctionality of the scan line corrector (SLC; its nonfunctionality is referred to as SLC-off), which causes gaps in the ETM+ data. On 31 May 2003, the SLC, which compensates for the forward motion of Landsat 7, failed, resulting in approximately $22 \%$ data loss [40]. The SLC-off effects gradually increase from the center of the scene toward the edges, where the effects are most conspicuous. The middle region of the scene, which is approximately $22 \mathrm{~km}$ wide on the ETM+ L1T data, contains almost no data loss; the quality of the middle region is very similar to that of Landsat ETM+ data with the SLC-on. In this study, the Rujigou coalfield is partly located in the middle of the scene, where the SLC-off effects are much less than in other parts of the scene (Figure 3a,b). In this paper, the SLC-off effects in the study area were corrected using a technique developed by Storey et al. $[28,40]$. The method is used to fill the gaps in one scene with data from another scene of Landsat data using a linear transform to the filling image to adjust it, based on the mean and standard deviation of each band of each scene [40]; details of the gap-filling method used in this study is referred to in the article on the gap-filling algorithm (phases one and two) by 
the USGS (2004) and Storey et al. [40]. With the help of Interactive Data Language (IDL) and the software Environment for Visualizing Images (ENVI, Manufactured by ITT Exelis, Inc., McLean, Washington, DC, USA), the gap-filling algorithm is coded in IDL and was used, with ENVI, to fill the gaps in the scenes. In this study, the SLC-on nighttime Landsat ETM+ data from 28 September 2002, was used to fill the gaps in the scenes of Landsat ETM+ data from 8 July 2007 (Figure 3c,d). To show the obvious contrast, image enhancement with a Gaussian algorithm was also performed (Figure 3e,f).

Figure 3. (a) SLC-OFF effects on the thermal band 6 data. (b) Gap-filling with the thermal band 6 data. (c) Image enhancing with Gaussian algorithm. (d) SLC-OFF effects on the SWIR band 6 data. (e) Gap-filling with the SWIR band 6 data. (f) Image enhancing with Gaussian algorithm.

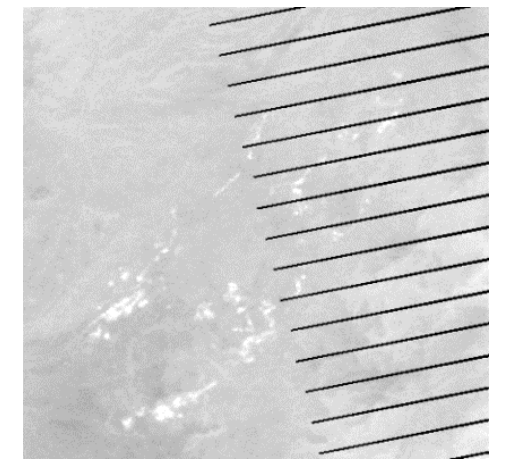

(a)

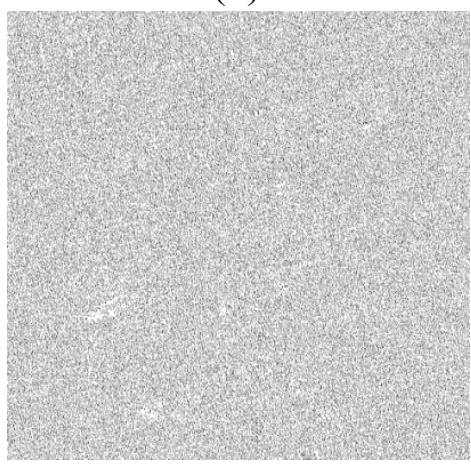

(d)

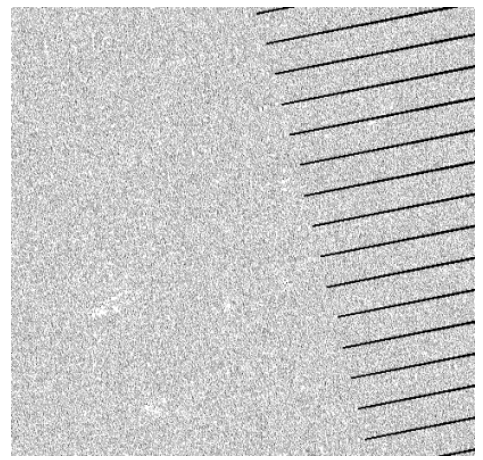

(b)

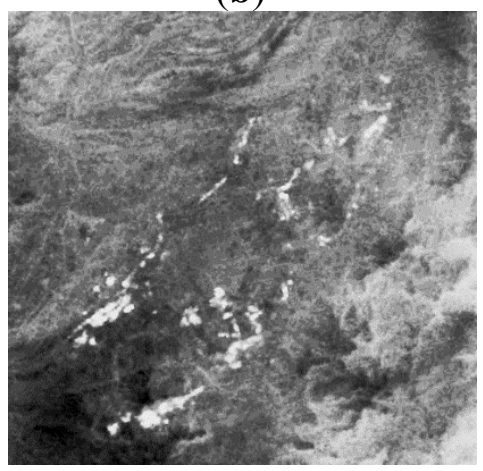

(e)

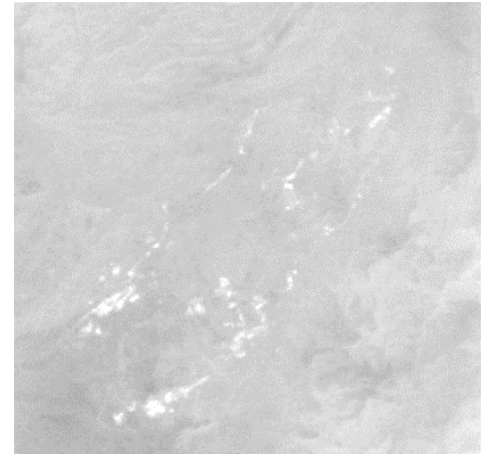

(c)

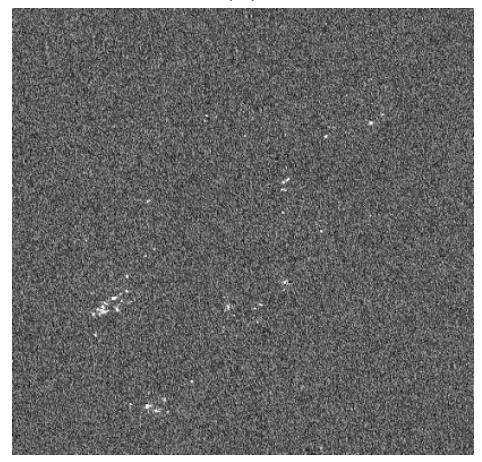

(f)

\section{Methodology}

The Landsat TIR band data have been used for detecting coal fires during the past several decades by many scientists, and in the study area, Rujigou coal field, Prakash A. et al. also developed a research with the Landsat TM thermal band 6 data and the DEM data and other ancillary datasets [41]. In this study, considering the spatial resolution of the TM band 6 data $(120 \mathrm{~m})$ being coarser than that of the ETM+ band 6 data, small and deep coal fires may not be detected, the Landsat ETM+ TIR (with a spatial resolution $60 \mathrm{~m}$ ) and SWIR (with a spatial resolution $30 \mathrm{~m}$ ) data were used to detect coal fire dynamics based on the different thresholding method. Landsat ETM+ produces two thermal band images with 60-m spatial resolution, including one thermal data with a low gain setting $(6 \mathrm{~L})$ and one with a high gain setting $(6 \mathrm{H})$. The $6 \mathrm{H}$ band has a lower saturation temperature $(322 \mathrm{~K})$ than the saturation of $6 \mathrm{~L}$ band $(347.5 \mathrm{~K})$. Therefore, the thermal data we chose to use in the study are the $6 \mathrm{~L}$ data. The nighttime ETM+ 
band 6 data are useful for distinguishing gross thermal anomalies from the background of solar warming and can be used to map subsurface coal fires. Using a series of multi-temporal nighttime ETM+ thermal band 6 images, we can predict the spreading direction of the underground coal fires. For thermal band 6 data, using Planck's law and related corresponding image preprocessing work, we retrieved the radiant temperatures from the ETM+ thermal data. To calculate the surface temperature, the land surface emissivity was derived from the Normalized Difference Vegetation Index (NDVI). Subsequently, the land surface temperature (LST) was retrieved from the ETM+ thermal band 6 data combining the emissivity, and the thermal-anomaly pixels were separated from the background pixels using a thresholding technique. For ETM+ SWIR band 7 data, the radiant temperature was calculated from the multi-temporal satellite data, based on Planck's law. Next, a simple thresholding technique was used to detect the surface coal fires from the resulting radiant temperatures. The official coal fire map produced by the field survey, resampled to the Universal Transverse Mercator (UTM) map projection and the World Geodetic System (WGS) 84 coordinate system used for the Landsat data, was used to validate the results obtained from the multi-temporal nighttime Landsat ETM + data. The spreading directions of the developing coal fires that we predicted closely matched the results of the field survey, and an attempt was made to quantitatively analyze the coal fire dynamics during the period from 2001 to 2007. Detailed information on the flowchart for coal fire detection and monitoring in the study is shown in Figure 4.

Figure 4. Flowchart of coal fire detection and monitoring in the study.

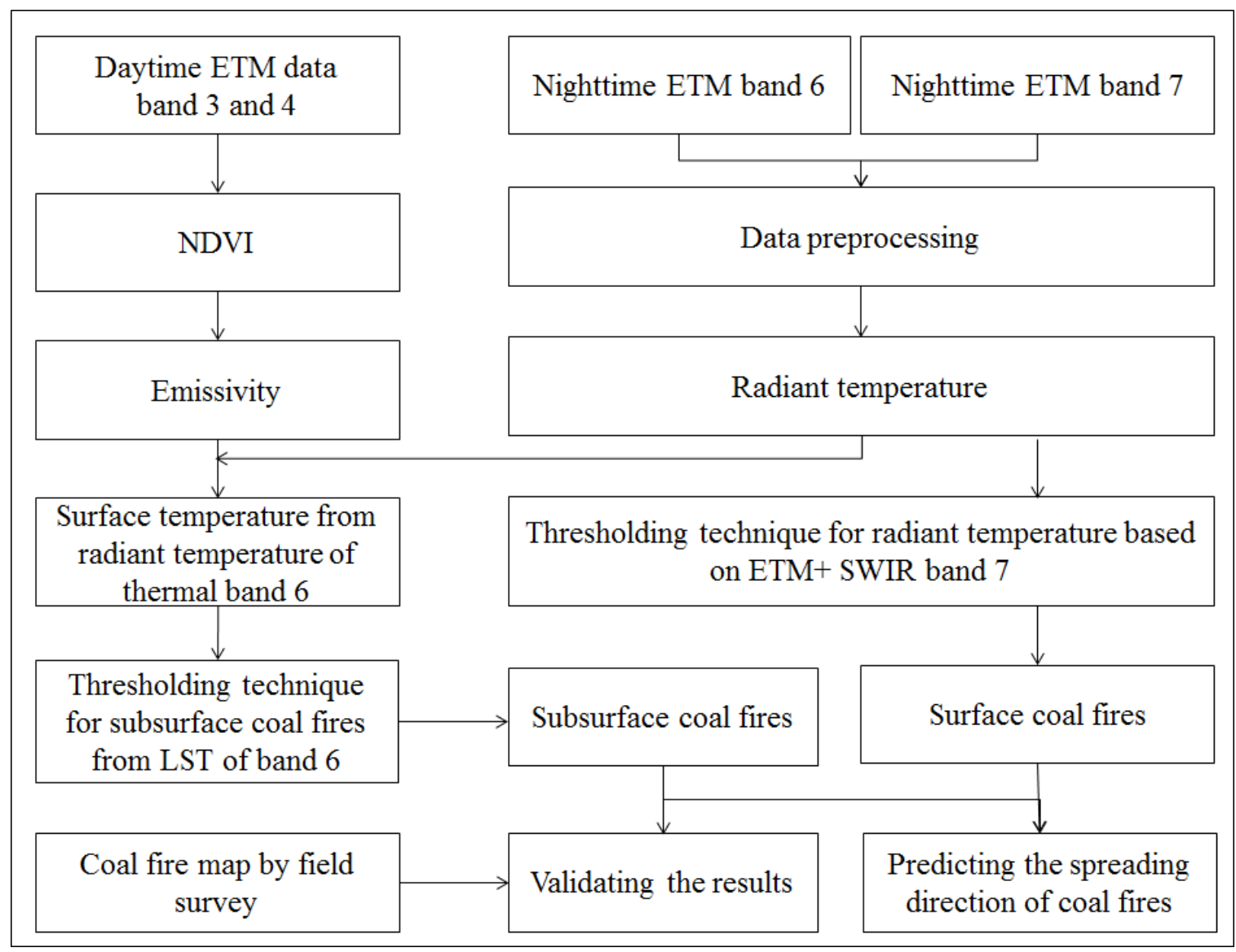


4.1. Surface Temperature Estimated from Thermal Band 6 Images and Radiant Temperature Calculated from SWIR Band 7 Images

Estimation of surface temperature from the ETM+ band 6 image occurs in three steps:

First, according to Planck's law relating spectral radiance $L_{\lambda}$ and the temperature, the spectral radiance can be described as follows:

$$
L_{\lambda}=\frac{\varepsilon C_{1} \lambda^{-5}}{\pi\left(\exp \left(\frac{C_{2}}{\lambda T}\right)-1\right)}
$$

Then, the inverse Planck equation:

$$
T=\frac{C_{2}}{\lambda \ln \left(\left(\left(\varepsilon C_{1}\right) /\left(\pi L_{\lambda} \lambda^{5}\right)\right)+1\right)}
$$

where $C_{1}$ and $C_{2}$ are constants, $C_{1}$ is equal to $3.742 \times 10^{-16} \mathrm{Wm}^{2}$ and $C_{2}$ is equal to $1.44 \times 10^{-2} \mathrm{mK}$. $\lambda$ is the wavelength in meters, $\varepsilon$ is the emissivity and $\mathrm{T}$ is the temperature in $\mathrm{K}$, Then, the radiant temperature can be simplified as follows:

$$
T_{R}=\frac{14400}{\lambda \ln \left(\frac{3.742 \times 10^{7}}{\pi \lambda^{5} L_{\lambda}}+1\right)}
$$

The second step was to, according to the following equation, convert the raw digital numbers (DN) to spectral radiance, $L_{\lambda}[42]$ :

$$
L_{\lambda}=L_{\min (\lambda)}+\frac{L_{\max (\lambda)}-L_{\min (\lambda)}}{Q_{c a l \max }} Q_{c a l}
$$

where $L_{\lambda}$ is the spectral radiance, $L_{\min (\lambda)}$ is the minimum detected radiance for the scene, $L_{\max (\lambda)}$ is the maximum detected radiance for the scene, $Q_{c a l}$ is the grey level for the analyzed pixel $(D N)$ and $Q_{\text {calmax }}$ is the maximum grey level. The values of $L_{\min (\lambda)}$ and $\mathrm{L}_{\max (\lambda)}$ used are given in the article by Chander et al. [43]. According to the metadata that accompanies the nighttime ETM+ images, the spectral radiance of band 6L thermal data and the SWIR band 7 data can be calculated by following equations:

$$
\begin{gathered}
L_{\text {thermal }}=0.0670866 \times D N \\
L_{\text {swir }}=0.0664961 \times D N-0.35
\end{gathered}
$$

where $L_{\text {thermal }}$ is the spectral radiance of the thermal band $6 \mathrm{~L}, L_{\text {swir }}$ is the spectral radiance of the band 7 image and $D N$ is the grey level for the analyzed pixel and is also the digital number of the image. Combining Equations (3), (5), and (6), we obtain the respective radiant temperature, $T_{R}$, of thermal band $6 \mathrm{~L}$ and the SWIR band 7.

The third step was to correct the atmospheric effects based on the method developed by Jiménez-Muñoz and Sobrino (2003), more detailed information can be found in [43], with this method, the atmospheric functions have been obtained for ETM+ band 6 data:

$$
\psi_{1}=0.14714 \omega^{2}-0.15583 \omega+1.1234
$$




$$
\begin{aligned}
& \psi_{2}=-1.1836 \omega^{2}-0.37607 \omega-0.52894 \\
& \psi_{3}=-0.04554 \omega^{2}+1.8719 \omega-0.39071
\end{aligned}
$$

where $\psi_{1}, \psi_{2}, \psi_{3}$ is the atmospheric function, and the $\omega$ is the atmospheric water vapor content in the thermal infrared region and it was estimated, in the study, from the MODIS level 2 product MOD05 (atmospheric water vapor content).

The fourth step is to indirectly calculate the emissivity from the NDVI using the following equation, which was firstly established by Van de Griend and Owe (1993), and further developed by Valor and Caselles (1996), and Sobrino and Raissouni (2000), and for more details can be found in [44-49]. In the study, the land surface coverage was mainly composed of small rivers, sparse vegetation surrounding the rivers, coal mines and coal waste processing plants, and almost bare natural surface. To accurately estimate the emissivity of land surface, the study area was classified into three categories of natural surface, rivers and buildings (such as coal mines, coal waste processing plants, etc.), based on a supervised method with Landsat ETM+ visible near infrared data (VNIR) and the panchromatic (PAN) band 8 images:

$$
\begin{aligned}
& \varepsilon_{N_{-} S}=0.9625+0.0614 P_{V}-0.0461 P_{V}^{2} \\
& \varepsilon_{B}=0.9589+0.086 P_{V}-0.0671 P_{V}^{2} \\
& \mathcal{\varepsilon}_{W}=0.995
\end{aligned}
$$

$$
\begin{gathered}
P_{V}=\frac{N D V I-N D V I_{M I N}}{N D V I_{M A X}-N D V I_{M I N}} \\
N D V I=\frac{\rho_{\text {red }}-\rho_{\text {nir }}}{\rho_{\text {red }}+\rho_{\text {nir }}} \\
\rho_{\lambda}=\frac{\pi \cdot L_{\lambda} \cdot d^{2}}{E_{\text {sun } \lambda} \cdot \cos \theta_{s}}
\end{gathered}
$$

where $\varepsilon_{N_{-}} S$ is the thermal emissivity of natural surfaces, $\varepsilon_{B}$ is the emissivity of buildings, $\varepsilon_{W}$ is the thermal emissivity of rivers, NDVI is the normalized difference vegetation index for individual surface covers, which can be obtained by Equation (9), and $\mathrm{P}_{v}$ is the vegetation cover in sparsely vegetated areas. In that study, $P_{v}$ was set to 0 when the value of NDVI was less than 0.05 , and $P_{v}$ was set to 1.0 when the value of the NDVI exceeded 0.7 . However, in the study area, the maximum value was counted at 0.48 ; therefore, only the first situation occurred in the study. $\rho_{\text {nir }}$ is the reflectance of the NIR band data, $\rho_{\text {red }}$ is the reflectance of the RED band data, $\rho_{\lambda}$ is the unitless planetary reflectance, $\pi$ is a mathematical constant equal to $\sim 3.14159$ (unitless), $d$ is the Earth-Sun distance (astronomical units), $L_{\lambda}$ is the spectral radiance, ESUN is the mean solar ex-atmospheric irradiance $\left(\mathrm{W} \cdot \mathrm{m}^{-2} \cdot \mu \mathrm{m}^{-1}\right)$ and $\theta_{S}$ is the solar zenith angle (degrees), which can be found in the header file of the ETM+ data. Before estimating the land surface emissivity, considering the process of calculating the NDVI and $\mathrm{P}_{v}$ partly reduced the atmospheric effects (as the ratio module could partly reduce the atmospheric effects), the atmospheric effects did not play a primary part in estimating the NDVI and the $\mathrm{P}_{v}$, and for further step, the variation of $\mathrm{P}_{v} \operatorname{did}$ not play an important role in the variation of emissivity according to the Equation (8), thus, in this step, the atmospheric correction was not taken consideration. 
The final step, based on the generalized single-channel method developed by Jiménez-Muñoz and Sobrino (2003), the LSTs was estimated using the following equations [44]:

$$
\begin{aligned}
& T_{s}=\gamma \times\left(\left(\psi_{1} \times L_{\text {sensor }}+\psi_{2}\right) / \varepsilon+\psi_{3}\right)+\delta \\
& \gamma=1 /\left(C_{2} L_{\text {sensor }} / T_{\text {sensor }}^{2}\left(\lambda^{4} L_{\text {sensor }} / C_{1} L_{\text {sensor }}+\lambda^{-1}\right)\right) \\
& \delta=-\gamma L_{\text {sensor }}+T_{\text {sensor }}
\end{aligned}
$$

where the Ts is the LSTs, Lsensor is the at-sensor spectral radiance which can be calculated by Equation (4), Tsensor is the at-sensor brightness temperature, $\lambda$ is the wavelength, $\mathrm{C} 1$ and $\mathrm{C} 2$ is the Planck's constant, $\mathrm{C}_{1}=1.9104 \times 10^{8} \Omega \cdot \mu \mathrm{m} \cdot \mathrm{m}^{2} \cdot \mathrm{sr}^{-1}, \mathrm{C}_{2}=1.43877 \times 104 \mu \mathrm{m} \cdot \mathrm{K}, \psi_{1}, \psi_{2}, \psi_{3}$ is the atmospheric function, which can be estimated by Equation (7)

By combining Equations (3), (5), and (7)-(12), we obtained the surface temperature of the thermal band $6 \mathrm{~L}$ image, and by combining Equations (3) and (6), we obtained the radiant temperature of the band 7 SWIR image.

\subsection{Method for Detecting Coal Fires and Monitoring Their Spreading Directions}

In the section, the dynamic thresholding technique, an automated method based on statistical parameters (detailed information was described in Section 4.2.1), was used to detect and monitor the subsurface coal fires based on the Landsat ETM+ thermal band 6 data because subsurface coal fires usually have lower temperatures (less than approximately $70{ }^{\circ} \mathrm{C}$ ) than surface coal fires, and the fixed thresholding technique (detailed information was described in Section 4.2.2) was developed to identify and monitor the surface coal fires based on the Landsat ETM+ SWIR band 7 images because the nighttime ETM+ SWIR data sets are insensitive to solar irradiance and have a broad sensitivity of $160-277^{\circ} \mathrm{C}$, which coincides with the temperature range of the surface coal fires $\left(150-250{ }^{\circ} \mathrm{C}\right)$. Using the multi-temporal nighttime satellite data, we identified the coal fire spreading directions by stacking coal fires identified in the satellite data from every pair of successive years using the stacking analysis technique for analyzing images in a sequence, with the help of the Geographic Information System (GIS) software ArcGIS (Environmental Systems Research Institute, Inc., Redlands, CA, USA).

\subsubsection{Dynamic Thresholding Technique for Detection of Subsurface Coal Fires Using Nighttime ETM+} Thermal Band 6L Data

The various times, climatic conditions, surface types, and intensities and depths of coal fires affect the temperatures retrieved from the multi-temporal thermal images. Therefore, a fixed threshold is not suitable for identifying coal fires, thus, a dynamic threshold was used in this study. A good review of common dynamic threshold setting techniques is presented by Raju et al. [50]. For example, the histogram method is one dynamic threshold setting technique. In this method, a change in the shape of the slope of the histogram is identified, and a hypothetical uniform histogram is projected; the corresponding point on the $\mathrm{x}$-axis is taken as the threshold. The histogram method has the advantage of being independent of radiometric information and statistical parameters [11]. The moving window algorithm is another dynamic threshold setting method for extracting coal fire information. In this method, the histograms are statistically analyzed, and the DN value that represents the first local minimum after the primary maximum is set as the threshold. Based on the literature pertaining to setting 
a dynamic threshold and the local climate conditions, but without considering the effect of solar irradiance on the nighttime images, we selected the automated method to use in our study. The automated method has commonly been used for discriminating coal fires [28,50]. This method uses statistical parameters to detect coal fires when the satellite data are radiometrically corrected. Statistical parameters such as the mean, $\overline{\mathrm{x}}$, and the standard deviation, $\sigma$, were used to set a threshold. Using this method, the threshold $(\overline{\mathrm{x}}+2 \sigma)$ was used to delineate the areas of the coal fires.

\subsubsection{Fixed Thresholding Technique for Surface Coal Fires Detection Using Nighttime ETM+ SWIR Band 7 Data}

Unlike the nighttime ETM+ thermal band 6 data, which has a low saturation of temperature (approximately $70{ }^{\circ} \mathrm{C}$ ), the nighttime ETM+ SWIR band 7 data has a higher sensitivity temperature range $\left(160-277^{\circ} \mathrm{C}\right)$. Furthermore, the nighttime satellite SWIR data avoids the effects of solar irradiance on the land surface. According to the literature and previous field measurements, the temperatures of coal fires in most coalfields in China range from $150{ }^{\circ} \mathrm{C}$ to $250{ }^{\circ} \mathrm{C}[6,38,51]$, which is the same as other coalfields in other coal-producing countries, such as the Jharia coalfield in India, where the surface coal fire temperatures also range from $150{ }^{\circ} \mathrm{C}$ to $250{ }^{\circ} \mathrm{C}[35,51]$. The temperature sensitivity of the ETM + SWIR band 7 data $\left(\sim 160{ }^{\circ} \mathrm{C}-277^{\circ} \mathrm{C}\right)$ matches very well with the range of temperatures of surface coal fires [18]. Unlike for the thermal band, the radiance emitted by surfaces at background surface temperatures $(\sim 270-340 \mathrm{~K})$ will not be significant in the NIR and SWIR spectral regions, and it does not saturate at the approximately $70{ }^{\circ} \mathrm{C}$ temperature limit of the SWIR spectral region. Therefore, surface coal fires may be identified directly and definitively from the background surface temperature based on the night SWIR images using a simple thresholding technique. Moreover, with a high spatial resolution of $30 \mathrm{~m}$ and without considering solar irradiance, detection and monitoring of surface coal fires are facilitated. In this study, the at-satellite temperatures were retrieved from the nighttime multi-temporal SWIR data, considering the contribution of emissivity within $2.22 \mu \mathrm{m}$ of the SWIR band 7 to the LST. The threshold for the surface coal fires is set at $423.15 \mathrm{~K}$; the corresponding DN value is at least 12 of the original ETM+ SWIR band 7 data.

\subsubsection{Identification of the Spreading Direction of Coal Fires}

The coal fire spreading direction can be identified based on the dynamics of coal fires and the spatial distribution of these fires found using the multi-temporal TIR remote sensing data. Based on the multi-temporal nighttime satellite data, we identified the coal fire spreading direction by stacking coal fires identified in the satellite data from each successive two-year pair using the stacking analysis technique, which refers to analyzing the images in sequence using ArcGIS. Using specialized GIS software such as ENVI and IDL (Manufactured by ITT Exelis, Inc., Boulder, Colorado, USA), we delineated the coal fires using the automated method. Using specialized GIS software and the overlay analysis technique, we performed a comparative analysis of the results of every two-year period. Ultimately, we developed a map of coal fire spreading direction based on the spatial distribution of these temperatures extracted from the TM/ETM+ band6 imagery. 


\section{Results and Discussions}

Using nighttime Landsat 7 ETM+ data from 2001, 2002, and 2007, the results of spectral radiance images were generated, based on respective calibration parameters (average gains and offset). From these radiance images, the radiant temperatures based on the long time series of nighttime satellite data were retrieved using Planck's law. The corresponding emissivities were then calculated from NDVI values based on the long time series of daytime satellite images whose acquisition times and seasons matched those of the nighttime images. The corresponding surface temperatures in 2001, 2002, and 2007 were calculated, based on the emissivities and their respective radiant temperatures. Using the dynamic thresholding technique, the relation of the thermal anomalies to subsurface coal fires was delineated using the LST retrieved from multi-temporal ETM+ thermal band 6 data (Figure 5). Using the fixed thresholding technique, the surface coal fires were delineated based on the radiant temperatures retrieved from multi-temporal ETM+ SWIR band 7 data (Figure 6). The coal fires extracted from the satellite images were validated using the field survey map of coal fires (Figure 7). Subsequently, a comparative analysis was conducted to identify the relationship between surface and subsurface coal fires in the same year (Figure 8). Based on the results of surface and subsurface coal fires, the spreading direction of these coal fires was delineated and predicted (Figure 9).

Figure 5. Subsurface coal fires extracted from the ETM+ thermal band 6 data of 2001, 2002, and 2007. (a) thermal anomalies related subsurface coal fires of 2001; (b) thermal anomalies related subsurface coal fires of 2002; (c) thermal anomalies related subsurface coal fires of 2007; (d) multi-layer thermal anomalies related subsurface coal fires of 2001, 2002, and 2007.



(a)

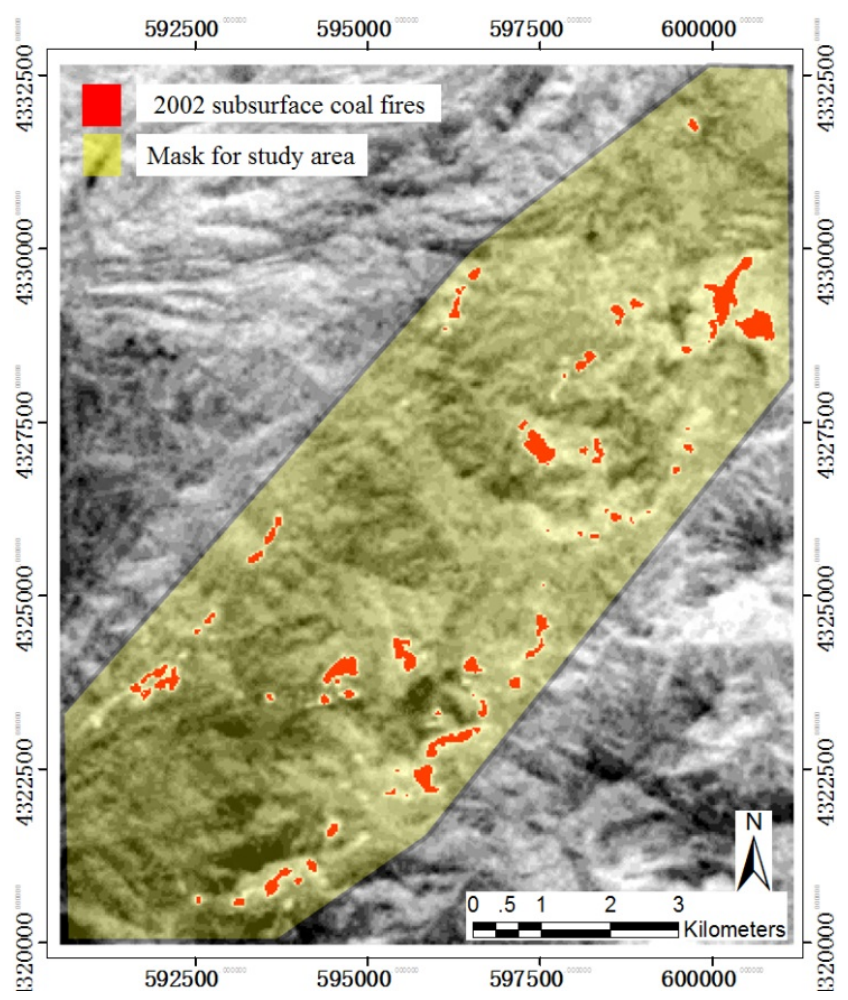

(b) 
Figure 5. Cont.

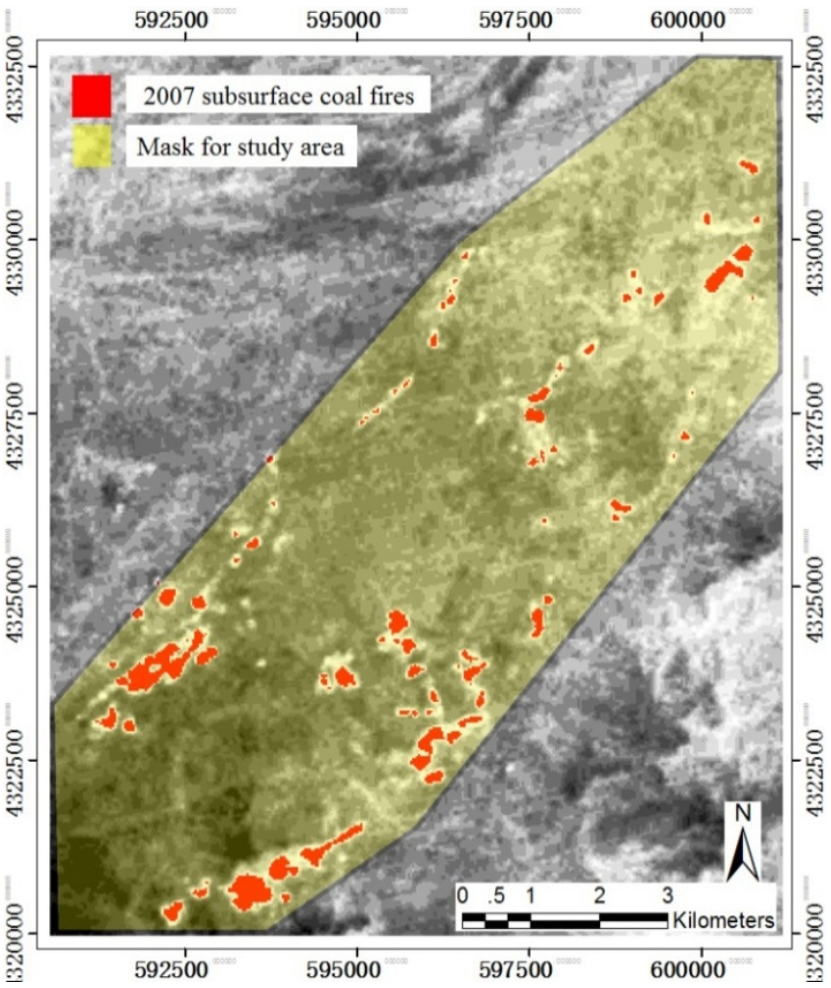

(c)

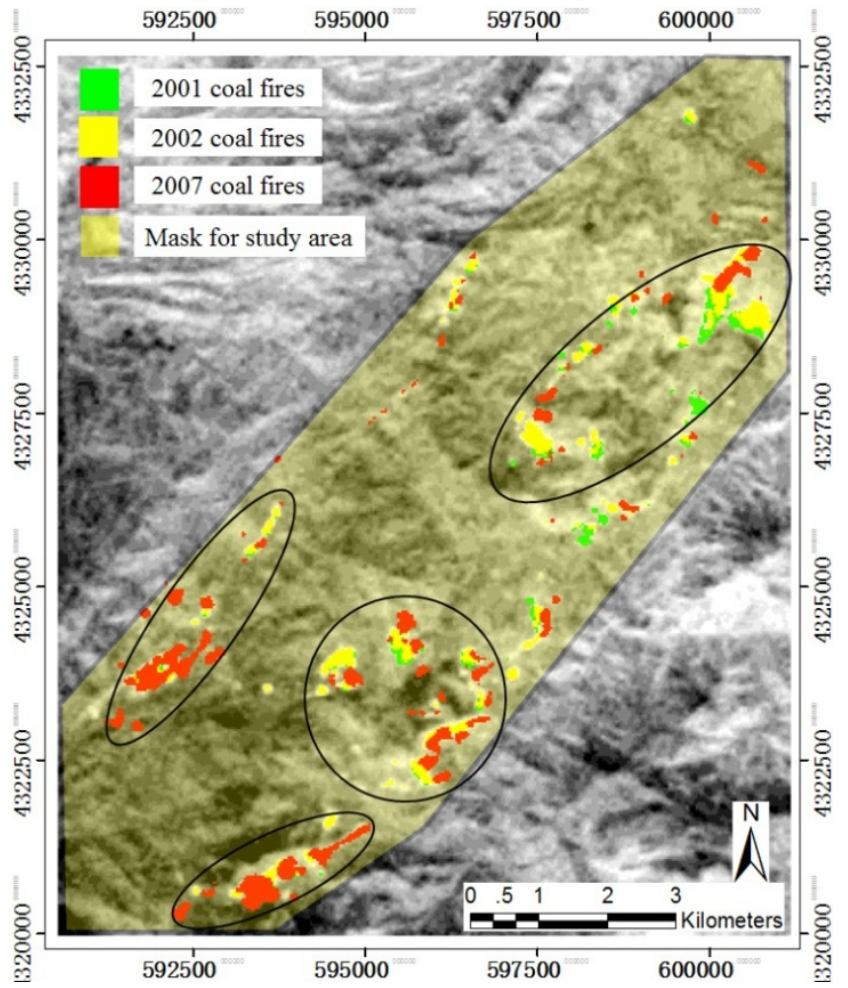

(d)

Figure 6. Surface coal fires extracted from the ETM+ SWIR band 7 data of 2001, 2002, and 2007. (a) surface coal fires of 2001; (b) surface coal fires of 2002; (c) surface coal fires of 2007; (d) multi-layer surface coal fires of 2001, 2002, and 2007.

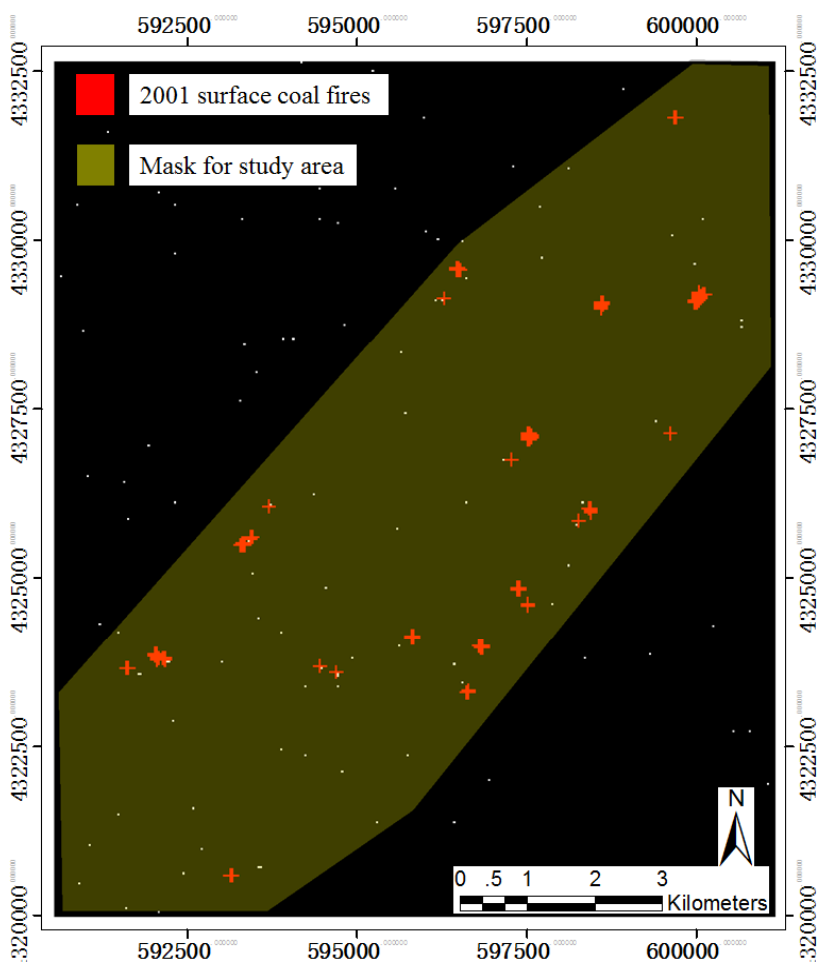

(a)



(b) 
Figure 6. Cont.

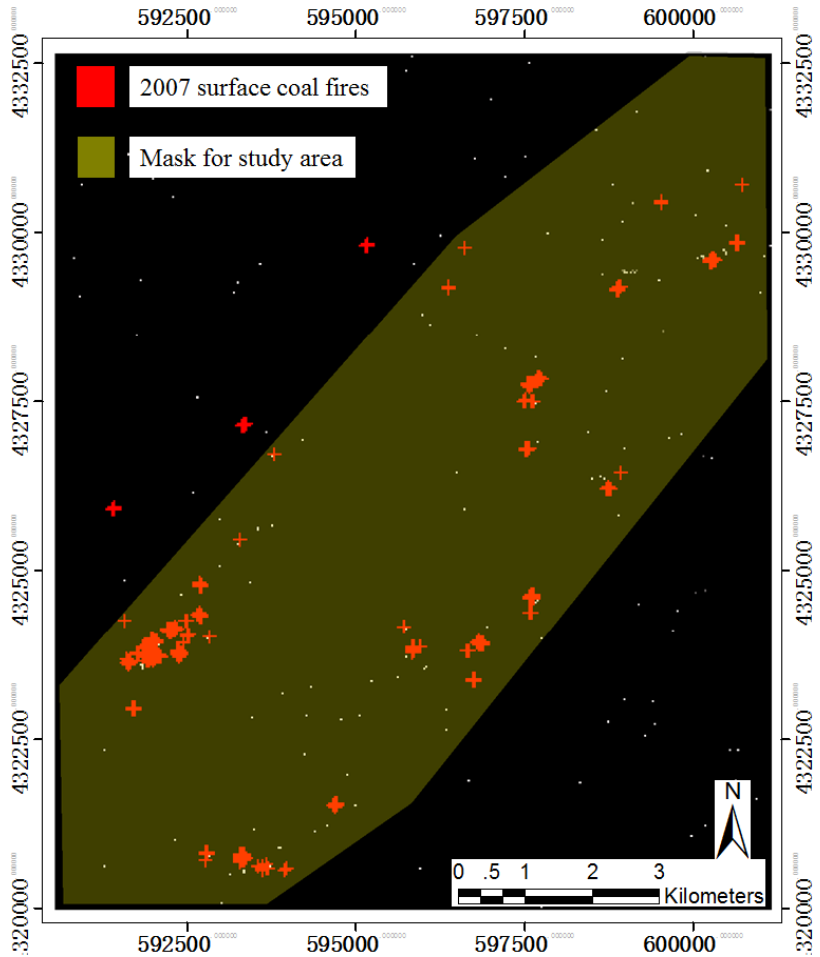

(c)

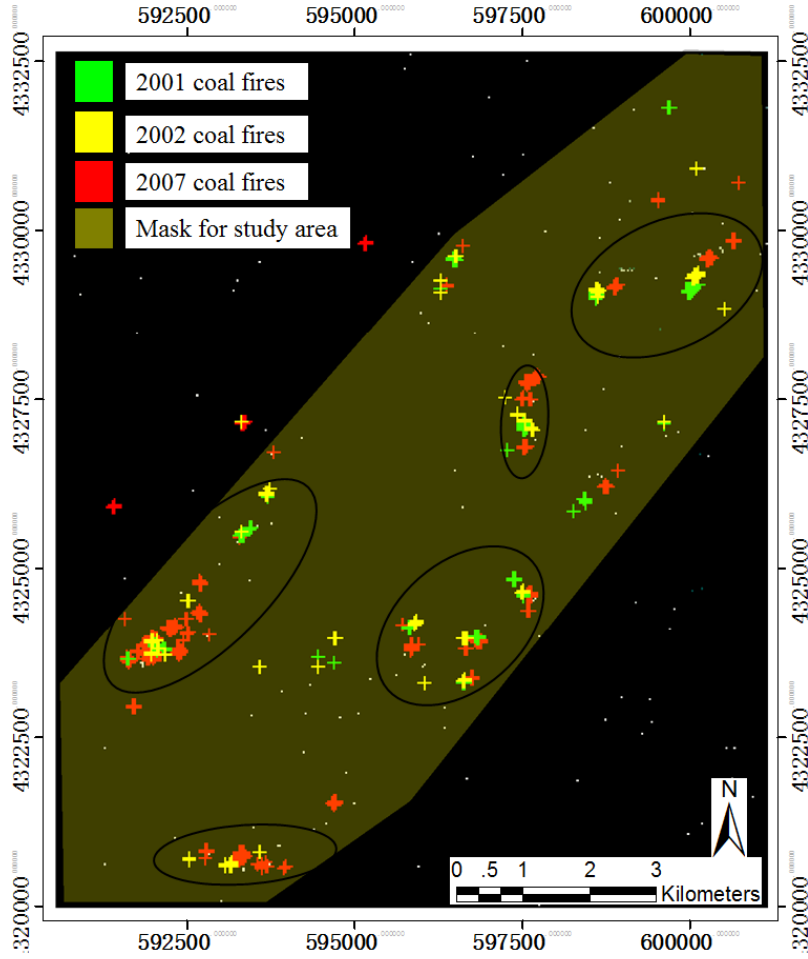

(d)

Figure 7. Validation of the results of coal fires extracted from the ETM+ data of 2002 by the field survey coal fire map which was developed during the time range of 2002 to 2003. (a) validation of coal fires from 2002 nighttime ETM+ data with CFM by field survey; (b) validation of coal fires from 2002 nighttime ETM+ data with CFM by field survey.

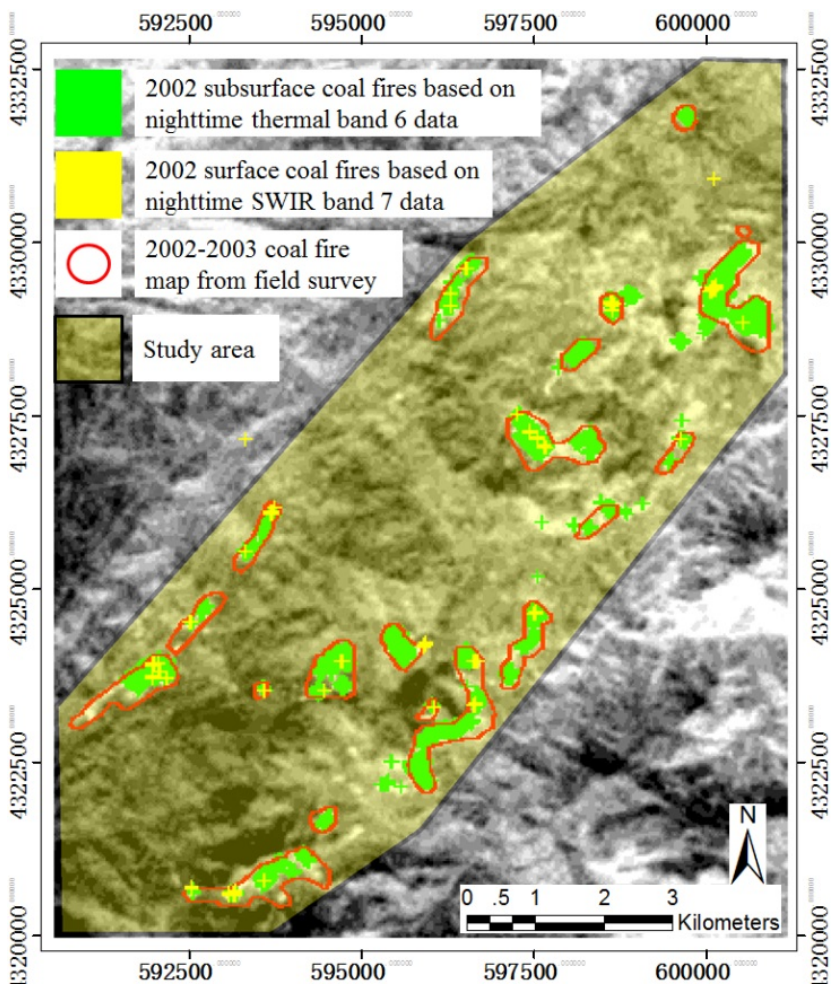

(a)

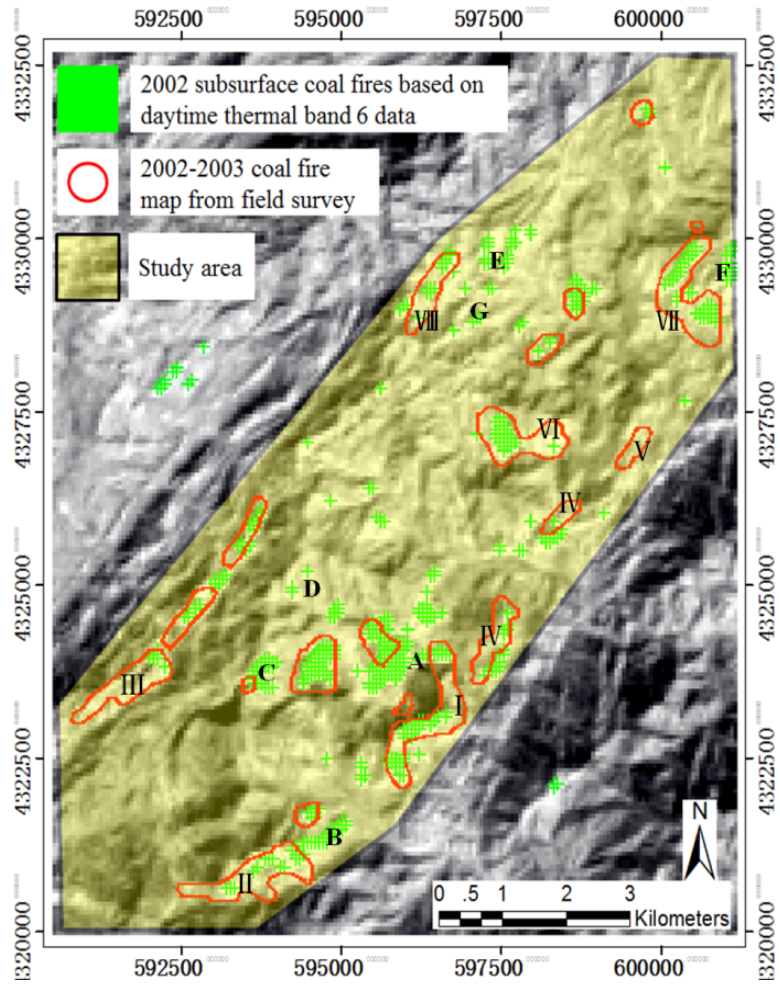

(b) 
Figure 8. Comparative analysis between the results of subsurface coal fires from thermal band 6 data and the respective results of surface coal fires from SWIR band 7 data.

(a) comparative analysis of results of surface coal fires and subsurface coal fires 2001;

(b) comparative analysis of results of surface coal fires and subsurface coal fires 2002;

(c) comparative analysis of results of surface coal fires and subsurface coal fires 2007;

(d) quantify the comparative analysis of results 1 and results 2, from 2001 to 2007.

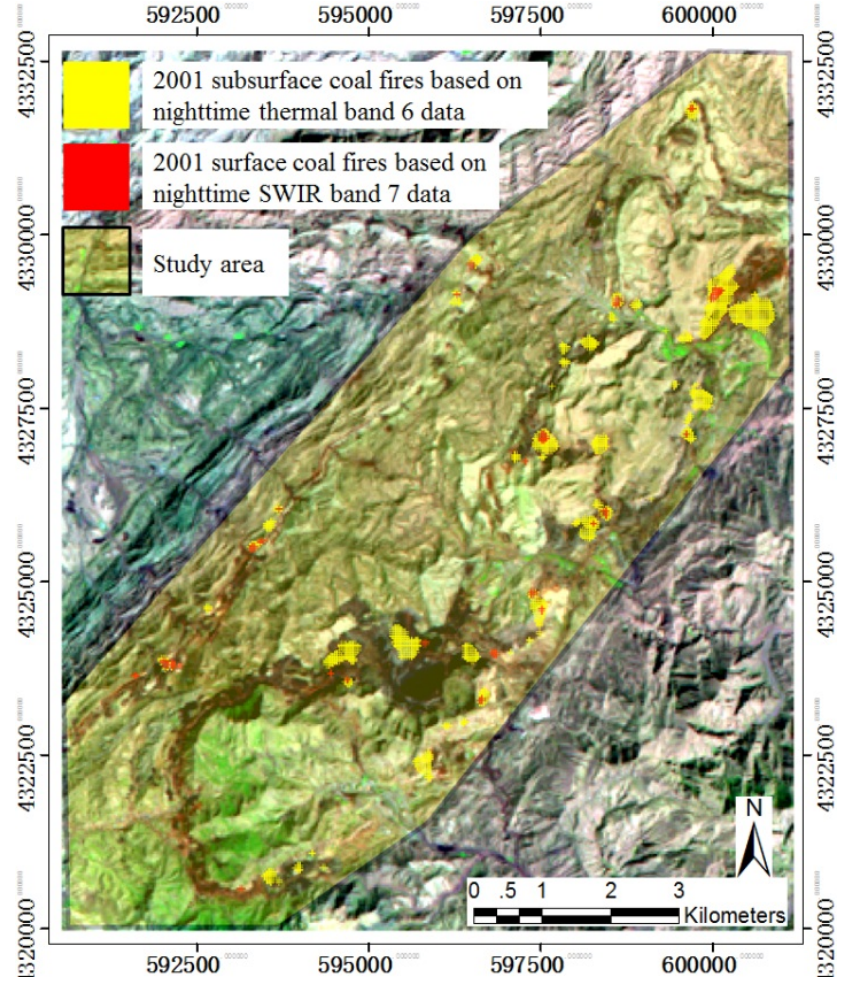

(a)

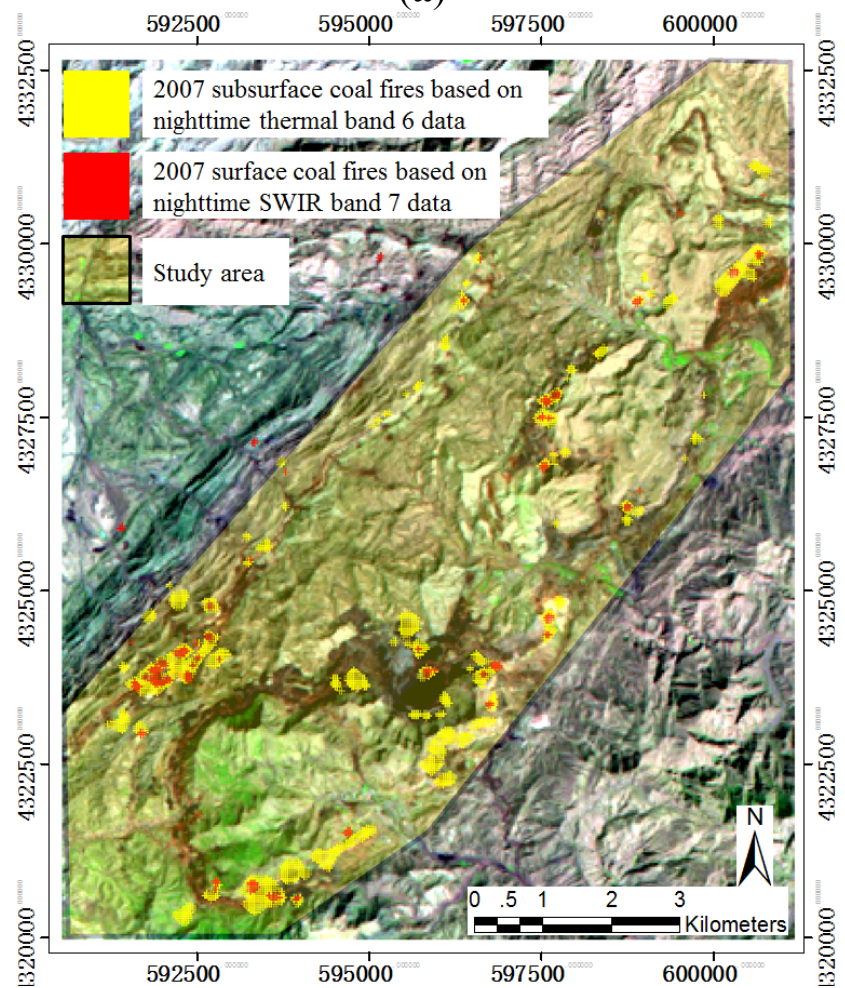

(c)

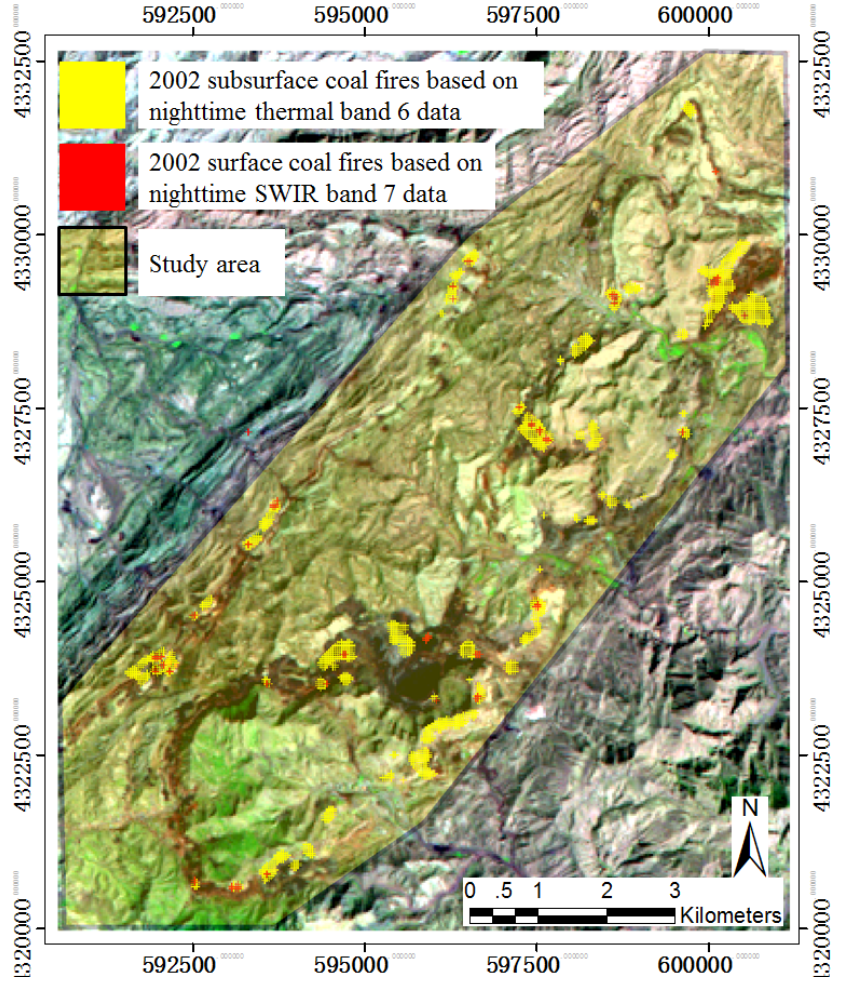

(b)

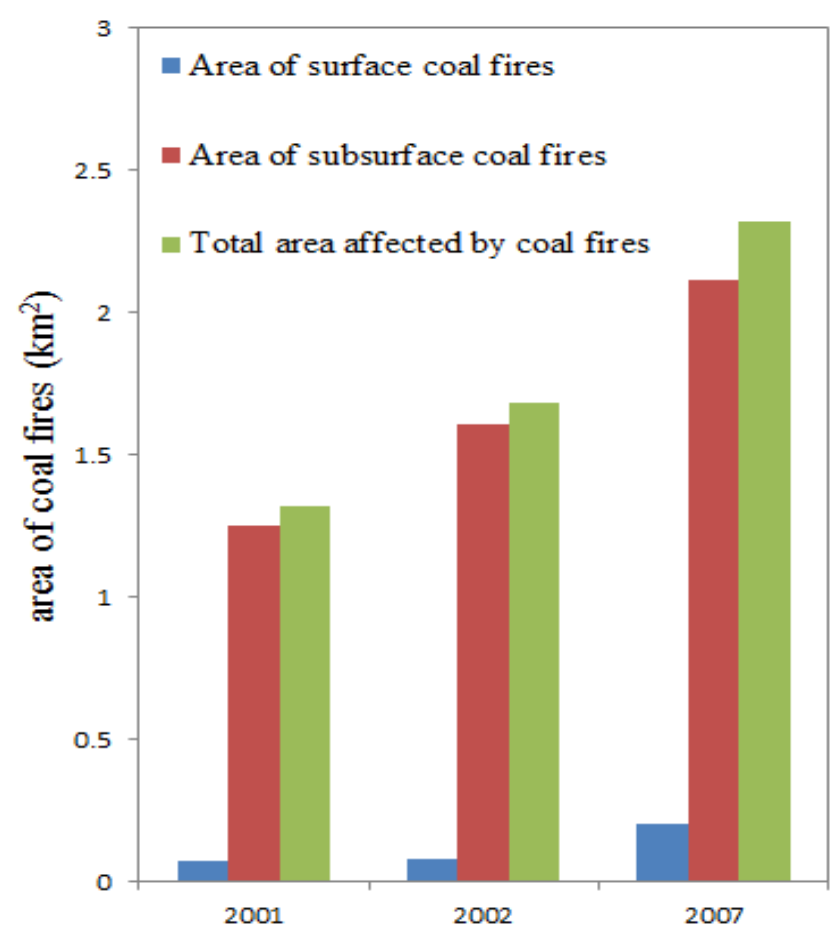

(d) 
Figure 9. Delineation and prediction of spreading direction of coal fires based on the results of surface coal fires and the subsurface coal fires respectively extracted from the Landsat ETM+ SWIR band 7 data and the thermal band 6 data.

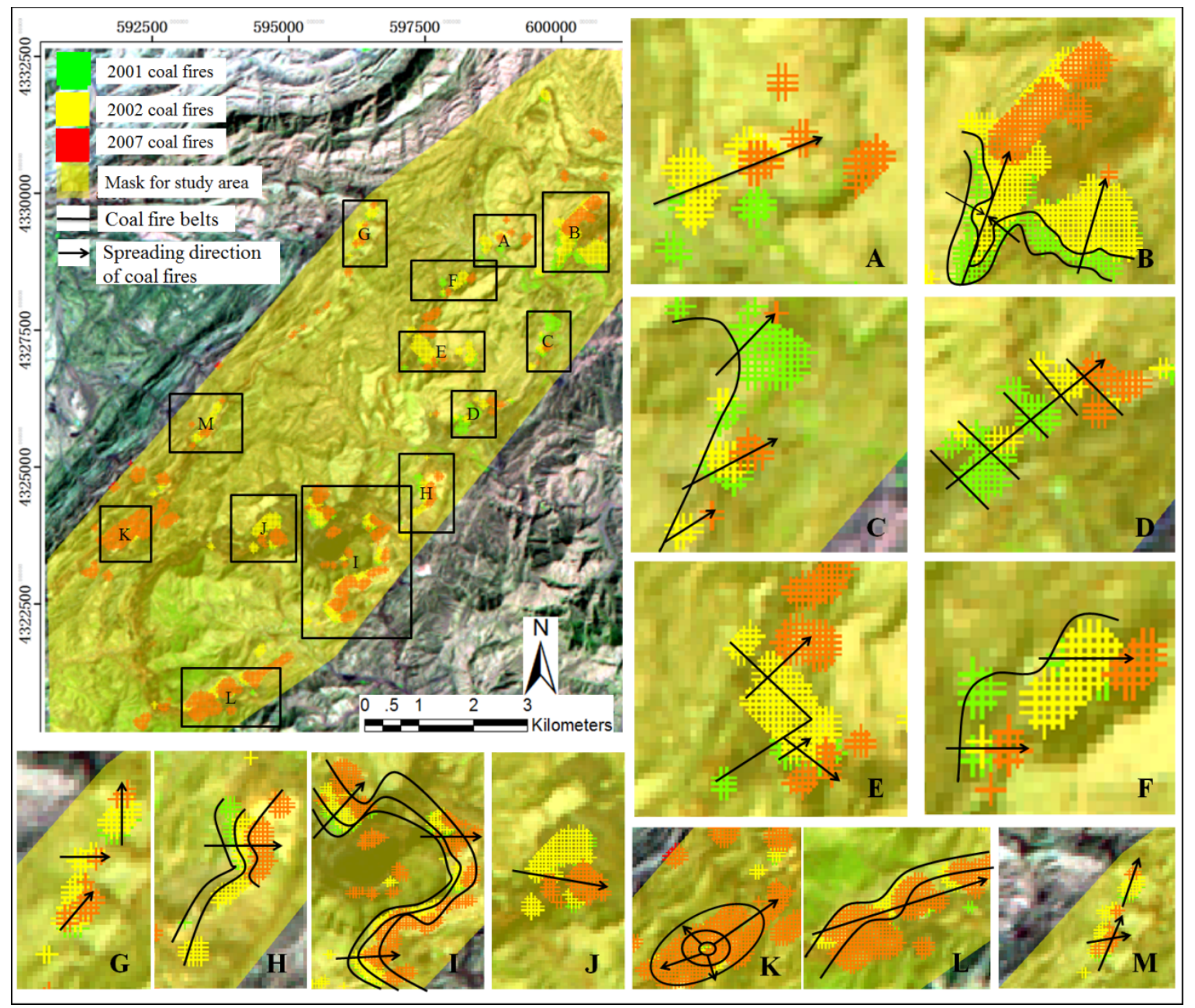

\subsection{Results 1: Subsurface Coal Fire Dynamics Based on ETM+ Thermal Band 6 Data}

Using the method described above, the locations of coal fires were extracted from the LST identified from the long time series of nighttime Landsat data from 2001 to 2007 (Figure 5a-c), and the results from this period were overlaid for comparative analysis (Figure $5 \mathrm{~d}$ ). The analysis also quantified the dynamics of the coal fires; the results are listed in Table 3. From the Table 3, we found that, unlike the surface coal fires, which have a very high temperature and can be easily detected with the temperature range $>423.15 \mathrm{~K}$ (somewhere above $150^{\circ} \mathrm{C}$ ) from the ETM+ SWIR band 7 data, the temperature ranges during which the subsurface coal fires were delineated from were different with the multi-temporal nighttime satellite data (e.g., the pixels' temperatures $>287.6 \mathrm{~K}$ in nighttime ETM+ band 6 data of 9 September 2001, were identified as surface coal fires, and the pixels' temperatures $>285.8 \mathrm{~K}$ in the nighttime ETM+ band 6 data of 28 September 2002, and the pixels' temperatures $>292.1 \mathrm{~K}$ in the nighttime ETM+ band 6 data of 8 July, 2007, were respectively identified as coal fires). In these Figures, obvious "zoning effects", where the thermal anomalies related to subsurface coal fires, can be seen, especially in 2007. Figure 5d shows that the coal fires were mainly concentrated within four areas (black circles in Figure 5d); the surface coal fires with these circles have obvious zoning effects. The spatial 
coverage of subsurface coal fires was found to be $1.248 \mathrm{~km}^{2}$ in $2001,1.607 \mathrm{~km}^{2}$ in 2002 , and $2.113 \mathrm{~km}^{2}$ in 2007. From Figure 5a-c and Table 3, we found that the area of the coal fires increased by $0.395 \mathrm{~km}^{2}$ from 2001 to 2002 and increased by $0.506 \mathrm{~km}^{2}$ from 2002 to 2007. As the nighttime Landsat ETM+ datasets are absent from 2003 to 2006, the annual average increasement of coal fires during the period of 2002-2007 can only be approximately estimated with the results of 2002 and the results of 2007. With the results of multi-temporal nighttime ETM+ data, we can infer that the average increase from 2002 to 2007 (approximately $0.1012 \mathrm{~km}^{2}$ per year) is smaller than the average increase from 2001 to 2002 (approximately $0.394 \mathrm{~km}^{2}$ per year). The reason for this may be that a program to control and extinguish the coal fires was implemented; it is reported that, over recent years, the Rujigou coal field had more than 20 coal fires, but with the efforts by the local administration to control them, 15 coal fires have been extinguished, according to previous articles and research [52]. Figure 5d shows the dynamics of coal fires during the period 2001-2007; this Figure also shows that many new coal fires developed every year. The main factors governing the risk of occurrence of these new coal fires might be the presence or absence of mining activities, the propensity of the coal to combust and access to oxygen, which, in turn, depends on the geochemical properties of the coal particle size, porosity, moisture content, and the concentrations of impurities.

Table 3. Subsurface coal fires related thermal anomalies extracted from ETM+ thermal band 6 data.

\begin{tabular}{cccccccc}
\hline \multicolumn{1}{c}{ Data Type } & Image Date & Min (k) & Max (k) & Mean (k) & Stdev (k) & Threshold (k) & Area (km $\mathbf{~}^{\mathbf{2}}$ \\
\hline Nighttime Landsat 7 & 9 September 2001 & 275.63 & 302.39 & 283.55 & 2.03 & 287.6 & 1.248 \\
Nighttime Landsat 7 & 28 September 2002 & 274.32 & 296.05 & 282.03 & 1.86 & 285.8 & 1.607 \\
Nighttime Landsat 7 & 8 July 2007 & 283.77 & 323.19 & 289.27 & 1.39 & 292.1 & 2.113 \\
\hline
\end{tabular}

\subsection{Results 2: Surface Coal Fire Dynamics Based on ETM+ SWIR Band 7 Data}

Using a fixed thresholding technique, surface coal fires were identified based on the results of the radiant temperature from the long time series of nighttime ETM+ SWIR band 7 data. To improve the detection of surface coal fires, the background noise was removed with a mask. Given that the threshold of $423.15 \mathrm{~K}$ for surface coal fires, which corresponds to a DN pixel value of at least 12 in the original ETM+ SWIR band 7 data, and when the DN pixel value is less than or equal to 8 (for which the radiant temperature is $390.38 \mathrm{~K}$; when $\mathrm{DN}$ is less than or equal to 6 , the radiant temperatures retrieved from the SWIR data were null), the information in the SWIR images is very weak. In this study, information in DN pixels with values less than or equal to 8 was regarded as noise and masked out (the black parts shown in Figure 6a-d). Figure 6a-c shows the surface coal fires of 2001, 2002 and 2007, respectively. The results of these three years were overlaid together for a comparative analysis using ArcGIS (Figure 6d). A quantitative analysis was conducted to show the dynamics of coal fire development; the results are listed in Table 4. These three figures show that the surface coal fires exhibit obvious "scattering effects", which are different from the "zoning effects" of the subsurface coal fires. The areas within the five black circles in Figure 6d show the obvious "scattering effects" of the surface coal fires. The spatial coverage of the surface coal fires was found to be $0.0702 \mathrm{~km}^{2}$ in $2001,0.0783 \mathrm{~km}^{2}$ in 2002 , and $0.2043 \mathrm{~km}^{2}$ in 2007, as listed in Table 4. From Figure 6a-c and Table 4, we inferred that the surface 
coal fires in 2001 and 2002 had almost the same area $\left(0.0702 \mathrm{~km}^{2}\right.$ and $0.0783 \mathrm{~km}^{2}$, respectively), which were both less than the area of coal fires in $2007\left(0.2043 \mathrm{~km}^{2}\right)$.

Table 4. Surface coal fires extracted from ETM+ short wave infrared (SWIR) band 7 data.

\begin{tabular}{cccc}
\hline Data Type & Image Date & Threshold $\mathbf{( k )}$ & Area $\left(\mathbf{k m}^{\mathbf{2}} \mathbf{)}\right.$ \\
\hline Nighttime Landsat 7 & 9 September 2001 & 423.15 & 0.0702 \\
Nighttime Landsat 7 & 28 September 2002 & 423.15 & 0.0783 \\
Nighttime Landsat 7 & 8 July 2007 & 423.15 & 0.2043 \\
\hline
\end{tabular}

\subsection{Validation of the Coal Fires Based on the Nighttime Series of Multi-Temporal ETM+Data}

A coal fire map obtained by field surveys over 2002-2003 was used to validate the coal fires extracted from the multi-temporal nighttime satellite data. With the help of ENVI and ArcGIS software, the subsurface coal fires identified from the thermal band 6 data, the surface coal fires identified from the SWIR band 7 data and the field survey map were overlaid together for comparative analysis (Figure 7). This figure shows that the surface and subsurface coal fires roughly coincide with the area of coal fires shown by the field map. The figure also shows that the results from the satellite data are very consistent with the results of the field-based coal fire map. There are some scattered coal fires not identified by the field-based map, which may be because of the time delay effects: the coal fires were extracted from 2002 satellite data, while the coal fire map was finished in 2003. Another reason for this may be that these coal fires were simply not found during the field investigation. In general, nighttime ETM+ thermal band 6 and SWIR band 7 data were proven to be a useful tool for the identification of high-temperature regions, which may help to pinpoint surface coal fire locations and potential subsurface coal fire locations, especially with the ETM+ SWIR band 7 data, which have a high sensitivity within the temperature range of $160-277^{\circ} \mathrm{C}$, which matches well with the surface coal fire temperature range of $150-250{ }^{\circ} \mathrm{C}$. This may facilitate the identification and discrimination of surface coal fire locations from the background noise based on the simple thresholding technique.

Table 5. Validation of results of coal fires from 2002 daytime satellite data and 2002 nighttime satellite data using coal fires map by field survey.

\begin{tabular}{ccccc}
\hline Data Type & Acquisition Time & Spatial Resolution (m) & Omission Error (\%) & Comission Error (\%) \\
\hline Nighttime ETM+ FSM & $\begin{array}{c}28 \text { September 2002 } \\
2002-2003\end{array}$ & 6060 & 15.2 & 4.5 \\
Daytime ETM+ FSM & $\begin{array}{c}21 \text { September 2002 } \\
2002-2003\end{array}$ & 6060 & 47.5 & 48.3 \\
\hline
\end{tabular}

FSM: Field Survey Map.

We compared the relationship between the coal fires identified from nighttime satellite data and the coal fires identified from daytime satellite data to further determine which type of satellite data is more useful for the identification of coal fires and their spreading directions. The locations of coal fires based on daytime ETM+ thermal band 6 data from 21 September 2002, were identified using the same method as applied to the nighttime ETM+ thermal band 6 data; these results were also validated using the field-based coal fire map obtained from the field survey (Figure $7 \mathrm{~b}$ ). Figure $7 \mathrm{~b}$ shows a less accurate identification of coal fires, due to both the omission error and the commission error, than that which was 
found using nighttime satellite data (Figure 7a). This comparative analysis showed that coal fires from daytime images had poor accuracy, as many pixels were misclassified as coal fires (e.g., the pixels within areas $A-G$ ), and many coal fires from daytime satellite data were not detected (e.g., some of the coal fires identified with the field survey map within the areas I-VIII were not detected). Details of the comparative analysis are listed in Table 5. From this information, we conclude that the coal fires identified from nighttime ETM + data were more accurate than those obtained from daytime ETM + data. Thus, nighttime data should be more useful, helpful and available than daytime images to detect and monitor the coal fires and will improve the accuracy of predicting coal fire spreading directions.

\subsection{Comparative Analysis of the Results 1 and the Results 2}

Surface coal fires identified from ETM+ SWIR band 7 data and subsurface coal fires identified from thermal band 6 data were stacked together using ArcGIS software to perform an overlay analysis to detect the relationship between them. Figure $8 \mathrm{a}-\mathrm{c}$ show the relationship between the surface and subsurface coal fires of 2001, 2002, and 2007, respectively. From these figures, we find that the surface coal fires (red color) obtained from the Landsat ETM+ SWIR band 7 data were almost entirely within the area of the coal fires (yellow color) obtained from the ETM+ thermal band 6 data aided by fixed threshold temperature modeling for a typical surface fire of mixed pixels, which shows the relevance of the model. However, there are some coal fires identified from the SWIR band 7 data scattered out of the area of the subsurface coal fires. The reason for this may be that the SWIR band 7 data has a higher spatial resolution $(30 \mathrm{~m})$ than the thermal band 6 data $(60 \mathrm{~m})$, which demonstrates that the nighttime ETM+ SWIR band 7 data can be used to detect hot anomalies (e.g., surface coal fires) that exceed the range of the ETM+ thermal band 6 data. Therefore, we conclude that the synergy between the surface coal fire area delineation algorithm based on the ETM+ SWIR band 7 data and the thermal anomalies related by the subsurface coal fire delineation algorithm, based on the ETM+ thermal band 6 data, were also apparent. Therefore, surface coal fires extracted from ETM+SWIR band 7 data and subsurface coal fires based on the ETM+ thermal band 6 data should be complementary to each other. The overall dynamic of coal fire areas is shown in Figure 8d, which shows that the total area of the net lateral propagation of coal fires from 2001 to 2007 is approximately $1 \mathrm{~km}^{2}$.

\subsection{Delineating the Spreading Direction of Coal Fires Based on the Results 1 and Results 2}

The spreading direction of coal fires is an important and critical input for controlling and monitoring them. Understanding the nature of coal fire propagation is also important for the administration of decision-making departments and for policy-makers to take necessary preventative measures for controlling and extinguishing the coal fires. In this study, to identify the coal fire spreading direction, attempts were made to delineate the general areas of coal fires at the coalfield scale based on the results of surface and subsurface coal fires from 2001 to 2007. Then, the coal fire spreading direction was delineated using the baselines of the identified coal belts. It is observed that during the period from 2001 to 2007, the spreading direction of coal fires was generally toward the north or northeast (e.g., coal fires within the areas A, C, D, E, and M, in Figure 9), while at some places the coal fires spread toward the east (e.g., coal fires within the areas F, G, H, J, and L, in Figure 9), and at some places the coal fires even spread inward from both the sides of the area of coal fires (e.g., coal fires within area B). The reason for 
this may be a close relationship between the distribution of coal beds and the direction of the coal seams. Some coal fires spread outward from a central point (e.g., coal fires within area K spread outward from a central point, from 2001 to 2007, which can be observed from the dynamics of subsurface coal fires in Figure 5a-c). There are also a few new coal fires scattered around the coal fire zones. The cause of this may be dense mining activity. There are also some coal fires scattered slightly farther away from the main coal fire zones. The cause of this may be the absence of nighttime images from 2003-2006, which could lead to corresponding coal fires not being identified; thus, the spreading direction of these remotely scattered coal fires could not be determined.

\section{Conclusions}

In this study, multi-temporal nighttime Landsat ETM+ thermal band 6 data and SWIR data from 2001 to 2007 with corresponding calibration parameters were used to calculate the spectral radiance. The spectral radiance was converted to the radiant temperature of the images using Planck's law. To retrieve the surface temperature, the emissivities were estimated from their respective NDVI values. As estimating the emissivity was not feasible in areas with NDVI values less than or equal to zero, we calculated the emissivities based on the method developed by Van de Griend and Owe (1993) [45] with the help of a supervised classification method that considered NDVI values to be less than or equal to zero. Subsequently, using the emissivity and the corresponding radiant temperatures, the surface kinetic temperatures were retrieved using the ETM+ thermal band 6 data. Based on the thresholding technique, the areas of subsurface and surface coal fires were delineated from ETM+ thermal band 6 and SWIR band 7 data, respectively, and the locations of coal fires were pinpointed.

From the multi-temporal coal fire map, the dynamics of coal fires during the period of 2001-2007 were calculated. The total area of coal fires increased from $1.3182 \mathrm{~km}^{2}$ in 2001 to $2.3173 \mathrm{~km}^{2}$ in 2007 , a net increase of approximately $1 \mathrm{~km}^{2}$. The subsurface coal fires increased from $1.248 \mathrm{~km}^{2}$ in 2001 to $2.113 \mathrm{~km}^{2}$ in 2007, and the surface coal fires increased from 72,000 $\mathrm{m}^{2}$ in 2001 to 204,300 $\mathrm{m}^{2}$ in 2007. During the validation of the results, we compared the coal fires identified from nighttime satellite data with the coal fires identified from daytime satellite data and found that the nighttime ETM+ data gave better accuracy than the daytime ETM+ data. Thus, nighttime ETM+ thermal data are more useful for coal fire identification and monitoring than daytime ETM+ thermal data. The nighttime ETM + thermal data were also more accurate for predicting the coal fire spreading direction.

A second comparative analysis of the relationship between the surface coal fires and the subsurface coal fires was conducted. It showed that most of the surface coal fires from ETM+ SWIR band 7 data were included in the subsurface coal fires obtained from ETM+ thermal band 6 data, as well as some surface coal fires scattered on the outskirts of the areas containing subsurface coal fires. The surface coal fires showed obvious "scattering effects" while the subsurface coal fires showed obvious "zoning effects". This situation is believed to show real information about the propagation of coal fires, as we know that most of the coal fires began to expand outwardly from just a few surface coal fires. This analysis also showed the synergic effects of the results from the ETM+ SWIR band 7 and thermal band 6 data.

The spreading direction of the coal fires was predicted from their dynamics from 2001 to 2007 . We found that, in general, most of the coal fires spread toward the north or northeast, while fires at some places spread toward the east. Temperature retrieval remains a useful tool for investigating surface and 
subsurface coal fires because of both its financial and practical attributes. This is especially true of the ETM+ thermal band 6 data and the SWIR band 7 data because the thermal band 6 data are up to date and have the highest spatial resolution $(60 \mathrm{~m})$ within the thermal region, as high as a commercial satellite, and the nighttime SWIR data have a broad sensitivity from 160 to $277^{\circ} \mathrm{C}$, which matches very well with the temperature ranges $\left(150-250^{\circ} \mathrm{C}\right)$ of surface coal fires.

However, there are some problems that need to be resolved with further research. An extensive field survey of the spatial distribution of coal fires should be performed, and the related field survey data should be collected in as much detail as possible. To obtain a more accurate spreading direction of coal fires, more nighttime long time series of satellite thermal data should be collected, and meteorological parameters such as wind direction at the acquisition time of the satellite data and related information such as the coal geology of the local environment and the terrain of the coal field should be considered. These parameters will help improve the understanding of the coal fire phenomenon and aid in the detection, depth estimation, monitoring, and management of coal fires.

\section{Acknowledgments}

This work was supported by the Strategic Pilot Scientific \& Technological Project of CAS (XDA05030200), by the national key basic research program (973 Program, 2013CB733402), by the National Natural Science Foundation of China (41231170), by the open fund project of Key Laboratory of Digital Earth, CAS (2012LDE018), and by the National Science and Technology Major Project (2011ZX05039-004). The authors also thank the US Geological Survey (USGS) for supplying data and advice. Hongyuan Huo is financially supported by Chinese Academy of Sciences for his study in ICube, CNRS, UdS, Strasbourg, France.

\section{Author Contributions}

All authors contributed equally to this work. Xiaoguang Jiang, Xianfeng Song and Zhao-Liang Li supervised the project. Xianfeng Song and Hongyuan Huo performed the field survey and validated the results with the field survey data. Zhuoya $\mathrm{Ni}$ and Caixia Gao performed the satellite datasets preprocessing. Hongyuan Huo performed analysis of the results with the programs developed by Zhuoya Ni and Caixia Gao. Hongyuan Huo wrote the paper. All authors discussed the results and implications and commented on the manuscript at all stages.

\section{Conflicts of Interest}

The authors declare no conflict of interest.

\section{References}

1. Banerjee, S.C. Spontaneous Combustion of Coal and Mine Fires; Balkema: Rotterdam, The Netherlands, 1985.

2. Schmal, D.; Duyzer, J.H.; van Heuven, J.W. A model for the spontaneous heating of coal. Fuel 1985, 64, 963-972. 
3. Guan, H.Y.; van Genderen, J.L.; Schalke, H.J.W.G. Study and Survey on the Geological Hazards of Coal Fire in Northern China. In Proceedings of the 30th International Geological Congress Abstract, Beijing, China, 4-14 August 1996; p. 458.

4. Peng, W.X.; van Genderen, J.L.; Kang, G.F.; Guan, H.Y.; Tan, Y.J. Estimating the depth of underground coal fires using data integration techniques. Terra Nova 1997, 9, 180-183.

5. Finkelman, R.B. Potential health impacts of burning coal beds and waste banks. Int. J. Coal Geol. 2004, 59, 19-24.

6. Zhang, J.; Wagner, W.; Prakash, A.; Mehl, H.; Voigt, S. Detecting coal fires using remote sensing techniques. Int. J. Remote Sens. 2004, 25, 3193-3220.

7. Gangopadhyay, P. Coalfire Detection and Monitoring in Wuda, North China: A Multi-Spectral and Multi-sensor TIR Approach. M.Sc. Thesis, International Institute for Geo-Information Science and Earth Observation (ITC): Enschede, The Netherlands, 2003.

8. Zhou, L.; Zhang, D.; Wang, J.; Huang, Z.; Pan, D. Mapping Land subsidence related to underground coal fires in the Wuda coalfield (Northern China) using a small stack of ALOS PALSAR differential interferograms. Remote Sens. 2013, 5, 1152-1176.

9. Van Genderen, J.L.; Cassells, C. The Synergistic use of remote Sensing data for the detection of Underground Coal fires. Int. Arch. Phogramm. Remote Sens. Spat. Inf. Sci. 1996, 31, 9-19.

10. Chen, Y.; Li, J.; Yang, B.; Shi, P.; Zhang, S. Detection of coal fire location and change based on multi-temporal thermal remotely sensed data and field measurements. Int. J. Remote Sens. 2007, 28, 3173-3179.

11. Rosema, A.; Guan, H.Y.; Veld, H.; Vekerdy, Z.; Ten Katen, A.; Prakash, A. Manual of Coal Fire Detection and Monitoring; Report of the Project: Development and Implementation of a Coal Fire Monitoring and Fighting System in China; Netherlands Institute of Applied Geoscience: Utrecht, The Netherlands, 1999; p. 245.

12. Künzer, C.; Zhang, J.; Voigt, S.; Center, G.R.S.D. Set up of a Spectral Database for Unmixing Approaches in Mining Environments in North-Central China: Demarcating Coal Fire Risk Areas. In EARSeL Workshop on Imaging Spectroscopy, 3rd ed.; EARSeL Secretariat: Hannover, Germany, 2003; pp. 344-348.

13. Zhang, X.; Kroonenberg, S.B.; de Boer, C.B. Dating of coal fires in Xinjiang, north-west China. Terra Nova 2004, 16, 68-74.

14. Dai, S.; Ren, D.; Tang, Y.; Shao, L.; Li, S. Distribution, isotopic variation and origin of sulfur in coals in the Wuda coalfield, Inner Mongolia, China. Int. J. Coal Geol. 2002, 51, 237-250.

15. Slavecki, R.J. Detection and Location of Subsurface Coal Fires. In Proceedings of the Third Symposium on Remote Sensing of Environment, Ann Arbor, MI, USA, 14-16 October 1964; pp. 537-547.

16. Sinha, P.R. Mine fires in Indian coalfields. Energy 1986, 11, 1147-1154.

17. Cracknell, A.P.; Mansor, S.B. Detection of sub-surface coal fires using Landsat TM data. Int. Arch. Phogramm. Remote Sens. Spat. Inf. Sci. 1993, 29, 4.

18. Prakash, A.; Gupta, R.P. Surface fires in Jharia coalfield, India-their distribution and estimation of area and temperature from TM data. Int. J. Remote Sens. 1999, 20, 1935-1946. 
19. Kuenzer, C.; Zhang, J.; Li, J.; Voigt, S.; Mehl, H.; Wagner, W. Detecting unknown coal fires: Synergy of automated coal fire risk area delineation and improved thermal anomaly extraction. Int. J. Remote Sens. 2007, 28, 4561-4585.

20. Greene, G.W.; Moxham, R.M. Aerial Infrared Surveys and Borehole Temperature Measurements of Coal Mine Fires in Pennsylvania. In Proceedings of the 6th Symposium on Remote Sensing of Envrionment (ERIM), University of Michigan, MI, USA, 13-16 October 1969; pp. 517-525.

21. Guan, H.Y.; Application of remote sensing techniques in coal geology. Acta Geol. Sinica 1989, 2, 253-269.

22. Rabchevsky, G.A. Determination from Available Satellite and Aircraft Imagery of the Applicatility of Remote Sensing Techniques to the Detection of Fires Burning in Abandoned Coal Mines and Unmined Coal Deposits Located in North Central Wyoming and Southern Montana; US Department of Interior, Bureau of Mines, Prepared by Allied Research Associates Inc.: Boston, MA, USA, 1972; p. 21.

23. Ellyett, C.D.; Fleming, A.W. Thermal infrared imagery of the burning mountain coal fire. Remote Sens. Environ. 1974, 3, 79-86.

24. Tan, K.; Zhou, R.; Wan, Y.; Li, X. Remote sensing monitoring method of hyperspectral and high-resolution for underground coal bed combustion. J. Infrared Millim. Waves 2007, 26, 349-352.

25. Zhang, X. Coal Fires in Northwest China, Detection, Monitoring, and Prediction Using Remote Sensing Data. Ph.D. Thesis, International Institute for Geo-Information Science and Earth Observation (ITC): Enschede, The Netherlands, 1998.

26. Künzer, C. Demarcating Coal Fire Risk Areas Based on Spectral Test Sequences and Partial Unmixing Using Multi Sensor Remote Sensing Data. Ph.D. Thesis, Technical University Vienna: Vienna, Austria, 2005.

27. Zhang, J. Spatial and Statistical Analysis of Thermal Satellite Imagery for Extraction of Coal Fire Related Anomalies. Ph.D. Thesis, Technical University Vienna, Vienna, Austria, 2004.

28. Tetzlaff, A. Coal Fire Quantification Using ASTER, ETM and BIRD Satellite Instrument Data. Ph.D. Thesis, Ludwig Maximilian University of Munich, München, Germany, 22 December 2004.

29. Yang, B.; Chen, Y.; Li, J.; Gong, A.; Kuenzer, C.; Zhang, J. Simple Normalization of Multi-Temporal Thermal IR Data and Applied Research, on the Monitoring of Typical Coal Fires in Northern China. In Proceedings of the 2005 IEEE International Geoscience and Remote Sensing Symposium, Seoul, Korea, 25-29 July 2005.

30. Gangopadhyay, P.K.; Maathuis, B.; van Dijk, P. ASTER-derived emissivity and coal-fire related surface temperature anomaly: A case study in Wuda, north China. Int. J. Remote Sens. 2005, 26, 5555-5571.

31. Prakash, A.; Gupta, R.P.; Saraf, A.K. A Landsat TM based comparative study of surface and subsurface fires in the Jharia coalfield, India. Int. J. Remote Sens. 1997, 18, 2463-2469.

32. Prakash, A.; Vekerdy, Z. Design and implementation of a dedicated prototype GIS for coal fire investigations in North China. Int. J. Coal Geol. 2004, 59, 107-119.

33. Agarwal, R.; Singh, D.; Chauhan, D.; Singh, K. Detection of coal mine fires in the Jharia coal field using NOAA/AVHRR data. J. Geophys. Eng. 2006, 3, 212-218. 
34. Bhattacharya, A.; Reddy, S. Underground and surface coal mine fire detection in India's Jharia coal field using airborne thermal infrared data. Asian-Pac. Remote Sens. J. 1994, 7, 59-73.

35. Reddy, C.S.S.; Srivastav, S.K.; Bhattacharya, A. Application of thematic mapper short wavelength infrared data for the detection and monitoring of high temperature related geoenvironmental features. Int. J. Remote Sens. 1993, 14, 3125-3132.

36. Saraf, A.K.; Prakash, A.; Sengupta, S.; Gupta, R.P. Landsat-TM data for estimating ground temperature and depth of subsurface coal fire in the Jharia coalfield, India. Int. J. Remote Sens. 1995, 16, 2111-2124.

37. Gangopadhyay, P.K. Coalfires Related CO2 Emissions and Remote Sensing; International Institute for Geo-Information Science and Earth Observation (ITC): Enschede, The Netherlands, 2008.

38. Zhang, X.; van Genderen, J.L.; Kroonenberg, S.B. A method to evaluate the capability of Landsat-5 TM band 6 data for sub-pixel coal fire detection. Int. J. Remote Sens. 1997, 18, 3279-3288.

39. Rothery, D.; Francis, P.; Wood, C. Volcano monitoring using short wavelength infrared data from satellites. J. Geophys. Res. 1988, 93, 7993-8008.

40. Storey, J.; Scaramuzza, P.; Schmidt, G.; Barsi, J. Landsat 7 Scan Line Corrector-Off Gap-Filled Product Development. In Proceedings of Pecora 16 Global Priorities in Land Remote Sensing, Sioux Fall, SD, USA, 23-27 October 2005.

41. Prakash, A.; Gens, R.; Vekerdy, Z. Monitoring coal fires using multi-temporal night-time thermal images in a coalfield in north-west China. Int. J. Remote Sens. 1999, 20, 2883-2888.

42. Markham, B.; Baker, J. EOSAT Landsat Technical Notes No. 1; EOSAT: Lanham, MD, USA, 1986.

43. Chander; Gyanesh; Brian L. Markham; Dennis L. Helder. Summary of current radiometric calibration coefficients for Landsat MSS, TM, ETM+, and EO-1 ALI sensors. Remote Sens. Environ. 2009, 113, 893-903.

44. Jiménez-Muñoz, J.C.; Sobrino, J.A. A generalized single-channel method for retrieving land surface temperature from remote sensing data. J. Geophys. Res.: Atmos. 2003, 108, doi: 10.1029/2003JD003480.

45. Van de Griend, A.; Owe, M. On the relationship between thermal emissivity and the normalized difference vegetation index for natural surfaces. Int. J. Remote Sens. 1993, 14, 1119-1131.

46. Valor, E.; Caselles, V. Mapping land surface emissivity from NDVI: Application to European, African, and South American areas. Remote Sens. Environ. 1996, 57, 167-184.

47. Sobrino, J.A.; Raissouni, N. Toward remote sensing methods for land cover dynamic monitoring: Application to Morocco. Int. J. Remote Sens. 2000, 21, 353-366.

48. Li, Z.-L.; Wu, H.; Wang, N.; Qiu, S.; Sobrino, J.A.; Wan, Z.; Tang, B.-H.; Yan, G. Land surface emissivity retrieval from satellite data. Int. J. Remote Sens. 2012, 34, 3084-3127.

49. Nerry, F.; Labed, J.; Stoll, M.P. Spectral properties of land surface in the thermal infrared 1. Laboratory measurement of absolute spectral emissivity signature. J. Geophys. Res. 1990, 95, 7027-7044.

50. Raju, A.; Gupta, R.P.; Prakash, A. Delineation of coalfield surface fires by thresholding Landsat TM-7 day-time image data. Geocarto Int. 2012, 4, 343-363.

51. Chatterjee, R.S. Coal fire mapping from satellite thermal IR data-A case example in Jharia Coalfield, Jharkhand, India. ISPRS J. Photogramm. Remote Sens. 2006, 60, 113-128. 
52. Kuenzer, C.; Zhang, J.; Tetzlaff, A.; van Dijk, P.; Voigt, S.; Mehl, H.; Wagner, W. Uncontrolled coal fires and their environmental impacts: Investigating two arid mining regions in north-central China. Appl. Geogr. 2007, 27, 42-62.

(C) 2014 by the authors; licensee MDPI, Basel, Switzerland. This article is an open access article distributed under the terms and conditions of the Creative Commons Attribution license (http://creativecommons.org/licenses/by/3.0/). 